\title{
Factors Determining the Subseasonal Prediction Skill of Summer Extreme Rainfall Over Southern China
}

\section{Junting Wu}

Nanjing University of Information Science and Technology

Juan Li ( $\square$ juanl@nuist.edu.cn )

Nanjing University of Information Science and Technology

Zhiwei Zhu

Nanjing University of Information Science and Technology

Pang-Chi Hsu

Nanjing University of Information Science and Technology

\section{Research Article}

Keywords: subseasonal prediction, boreal summer intraseasonal oscillation, extreme rainfall over southern China, S2S models

Posted Date: September 29th, 2021

DOl: https://doi.org/10.21203/rs.3.rs-922865/v1

License: (c) (i) This work is licensed under a Creative Commons Attribution 4.0 International License. Read Full License 


\title{
Factors Determining the Subseasonal Prediction Skill of Summer Extreme Rainfall over Southern China
}

\author{
Junting Wu ${ }^{1}$, Juan $\mathrm{Li}^{1,2^{*}}$, Zhiwei Zhu ${ }^{1}$, Pang-Chi Hsu ${ }^{1}$ \\ 1, Key Laboratory of Meteorological Disaster, Ministry of Education (KLME)/Joint \\ International Research Laboratory of Climate and Environment Change \\ (ILCEC)/Collaborative Innovation Center on Forecast and Evaluation of \\ Meteorological Disasters (CIC-FEMD), Nanjing University of Information Science \\ and Technology, Nanjing, China, 210044 \\ 2, State Key Laboratory of Numerical Modeling for Atmospheric Sciences and \\ Geophysical Fluid Dynamics (LASG), Institute of Atmospheric Physics, Chinese
} Academy of Sciences, Beijing, China, 100029

Submitted to Climate Dynamics on 19 September, 2021

Corresponding author: Juan Li, Nanjing University of Information Science and Technology, 219 Ningliu Road, Meteorology Bldg. Nanjing, 210044, China. E-mail: juanl@nuist.edu.cn 


\begin{abstract}
The occurrence of summer extreme rainfall over southern China (SCER) is closely related with the boreal summer intraseasonal oscillation (BSISO). Whether the operational models can reasonably predict the BSISO evolution and its modulation on SCER probability is crucial for disaster prevention and mitigation. Here, we find that the skill of subseasonal-to-seasonal (S2S) operational models in predicting the first component of BSISO (BSISO1) might play an important role in determining the forecast skill of SCER. The systematic assessment of reforecast data from the S2S database show that the ECMWF model performs a skillful prediction of BSISO1 index up to 24 days, while the skill of CMA model is about 10 days. Accordingly, the SCER occurrence is correctly predicted by ECMWF (CMA) model at a forecast lead time of $~ 14$ (6) days. The diagnostic results of modeled moisture processes further suggest that the anomalous moisture convergence (advection) induced by the BSISO1 activity serves as the primary (secondary) source of subseasonal predictability of SCER. Once the operational model well predicts the moisture convergence anomaly in the specific phases of BSISO1, the higher skill for the probability prediction of SCER is obtained. The present study implies that a further improvement in predicting the BSISO and its related moisture processes is crucial to facilitating the subseasonal prediction skill of SCER probability.
\end{abstract}

Keywords subseasonal prediction; boreal summer intraseasonal oscillation; extreme rainfall over southern China, S2S models 


\section{Introduction}

Southern China (SC), which is affected by the East Asian summer monsoon, features complex and varied weather and climate systems (Li et al. 2020a). The extreme rainfall is one of the most severe disastrous weather events in SC during summer, which could lead to flood, landslide, debris flow and other secondary disasters, and result in infrastructure damage and casualties (Li and Wang. 2018; Wang et al. 2021; Yang et al. 2021a).

Accurate prediction of extreme rainfall at longer lead time (beyond 10 days) has important meaning for better disaster prevention and mitigation (Zhang et al. 2021). However, because of the imperfectness of numerical models (e.g., errors in data assimilation techniques, initialization schemes and parameterizations) (Liang and Lin. 2018; Pegion et al. 2019), the subseasonal prediction (at a forecast lead time of 2 to 6 weeks) skills based on current numerical models cannot meet the demand of meteorological services yet. Understanding the source of subseasonal predictability and improving the model skills at this timeframe bring in grand challenge for both scientific and operational communities worldwide (Brunet et al. 2010; Lee and Wang 2016; Liu et al. 2020a).

Extreme rainfall, which are associated with anomalous large-scale circulation, are often modulated by atmospheric intraseasonal variations (Lau et al. 1988; Liu et al. 2008; Chen and Zhai 2017; Ji et al. 2021). As the dominant mode of subseasonal variations in the tropical atmosphere (Madden 1986; Chen and Chen 1993; 1995), the tropical intraseasonal oscillation (ISO, or the Madden-Julian Oscillation) activity exerts local and remote impacts on weather/climate systems worldwide (Matthews et al. 2004; Zhang 2005; Stan et al. 2017; Hsu et al. 2021). During boreal summer, the eastward-propagating characteristic of ISO becomes weaker whereas the northward 
propagation from the equator into the Asian summer monsoon (ASM) region is prominent, regulating the dry and wet phases of monsoon rainfall (e.g., Webster et al. 1998; Annamalai and Slingo 2001; Moon et al. 2013; Hu et al. 2017; Liu et al. 2020b; Li et al. 2021; Liu and Zhu 2021) and extremes over ASM (Hsu et al. 2016; 2017; Lee et al. 2017; Yao et al. 2020). These northward-propagated ISOs are referred commonly to as the boreal summer intraseasonal oscillation (BSISO, Lee et al. 2013). For better monitoring and predicting the BSISO over the ASM region (approximately $0^{\circ}-40^{\circ} \mathrm{N}, 40^{\circ}-160^{\circ} \mathrm{E}$ ), Lee et al. (2013) proposed two BSISO indices based on the four leading Empirical Orthogonal Function (EOF) modes of daily mean outgoing longwave radiation (OLR) and 850-hPa zonal wind (U850) anomalies over the ASM region. The first index of BSISO (BSISO1), consisting of the first two EOF modes, effectively represents the canonical northward and northeastward propagation feature of BSISO over the Indian Ocean with a period of 30-60 days. The second BSISO index (BSISO2) is defined by the combination of the third and fourth EOF modes, which mainly captures the northward and northwestward propagating ISO characteristic with a period of 10-30 days. Statistical analyses show that the probability of rainfall and heat extremes over the Asian monsoon regions, including southern China, India, and Northeast Asia, is notably modulated by BSISO1 and BSISO2 (Hsu et al. 2016; 2017; Lee et al. 2017; Yao et al. 2020). This provides a potential of real-time forecast for rainfall/temperature based on their relation with BSISO (Lee et al. 2017; Wang et al. 2020).

Accurate prediction of atmospheric intraseasonal variations, such as BSISO, especially the extreme events $10-30$ days in advance is imperative and is the main target of the subseasonal to seasonal (S2S) prediction project (Vitart et al. 2017). The S2S project establishes an extensive database (the S2S Database), including 
subseasonal (up to 60 days) forecasts and reforecasts from 11 operational and research centers (Vitart et al. 2017), providing a wide platform to study the intraseasonal issues. Thus, many studies have been carried out based on this database. Jie et al. (2017) found that the S2S models can effectively predict BSISO1 and BSISO2 events up to 6-24.5 and 6.5-14 day in advance, respectively. However, there is still a large room to improve BSISO since multi-model mean prediction skill is much lower than the potential/theoretical predictability of BSISO (Ding et al. 2011; Lee et al. 2015). Most models show deficiency in simulating the spatial structure, evolution, propagation, and intensity of BSISO (He et al. 2019; Bo et al. 2020; Zhu et al. 2021; Fang et al. 2019). The subseasonal prediction skills of rainfall and extreme rainfall are also limited. For the global weekly-mean precipitation over land, the forecast skills from most S2S models are confined in the first week (de Andrade et al. 2019). The significant prediction skills of South Asian Monsoon and Southeast Asian Monsoon rainfall are only up to about 2.5 days (Jie et al. 2017). The summer weekly-mean East Asian precipitation can be predicted significantly up to 5-11 days in advance (Liang and Lin 2018), meanwhile, the biases in predicting the subseasonal variability of East Asian summer rainfall are also exist (Fang et al. 2019). Although the ECMWF model's preperformances are generally better than others (Fu et al. 2013; Jie et al. 2017; He et al. 2019), it is still hard for the ECMWF model to capture the recordbreaking Meiyu rainfall event in 2020, with anomaly correlation coefficient lower than 0.5 (Liu et al. 2020a).

Previous studies mainly focused on the evaluation of model performance in simulating BSISO index and subseasonal rainfall variation, while less attention has been paid to discussing the source of subseasonal predictability of extreme rainfall. Considering the observed association between BSISO and extreme rainfall, whether 
the prediction skill of extreme rainfall is linked with the prediction skill of BSISO needs to be further examined. Through what key processes that the BSISO influences the extreme rainfall prediction in the S2S operational models is also an important issue, which helps to identify the source of biases in prediction.

In this paper, we aim to systematically assess the prediction skill of BSISO1 and SCER, including the deterministic and probabilistic prediction capability revealed from the reforecast data of two S2S operational models. Then, the sources of the associated prediction biases are diagnosed and discussed. This work is a basic but crucial step towards improving the current S2S prediction systems for predicting the high-impact extreme weathers at the subseasonal timescale.

\section{Data and methods}

\subsection{Observational data}

The observational datasets used in this study are as follows: 1) The daily mean precipitation data from gauge stations over China gridded into a horizontal resolution of $0.25^{\circ} \times 0.25^{\circ}$, which is provided by the National Meteorological Information Center (CN05.1, Wu and Gao 2013), and the Asian Precipitation Highly-Resolved Observational Data Integration Towards Evaluation (APHRODITE) gridded precipitation (Yatagai et al. 2012) with a $0.25^{\circ}$ horizontal resolution are adopted. To reduce the uncertainty arising from different data, a simple arithmetic average of these two precipitation datasets is applied. 2) The ERA-Interim reanalysis dataset (Dee et al. 2011) including daily mean wind and specific humidity is used, with its horizontal resolution being $1.5^{\circ} \times 1.5^{\circ} .3$ ) We also employ the real-time BSISO index proposed by Lee et al. (2013) (http://iprc.soest.hawaii.edu/users/jylee/bsiso/), which better 
represents the northward propagation of ISO during boreal summer than the Real-time Multivariate MJO index (RMM, Wheeler and Hendon 2004).

Using the principal component (PC1 and PC2) time series of the BSISO1 index, the life cycle of BSISO1 are divided into 8 phases. The active BSISO days are defined when the normalized BSISO1 amplitude is greater than 1 (i.e., $\sqrt{\mathrm{PC}^{2}+\mathrm{PC} 2^{2}}>1.0$ ). In contrast, an inactive BSISO1 (or non-BSISO1) period is identified when its amplitude is smaller than 1, during which the BSISO1 signals are weakened and less organized. Note that the phases 2-4 of BSISO1 are highly connected with the extreme rainfall occurrence over southern China (Lee et al. 2013; Hsu et al. 2016). In this article, the model prediction skill in these specific phases of BSISO1 and the associated SCER probability will be mainly focused.

Because the extreme rainfall over $\mathrm{SC}\left(18^{\circ}-32.5^{\circ} \mathrm{N}, 105^{\circ}-122^{\circ} \mathrm{E}\right)$ and enhanced BSISO activity are observed during the boreal summer monsoon season (May to August, hereafter MJJA), the MJJA during 1998-2012 is selected as the target period for prediction assessment in this study.

\subsection{S2S model data}

The reforecast data from two operational centers, the European Centre for Medium-range Weather Forecasts (ECMWF) and the China Meteorological Administration (CMA), are derived from the S2S database (http://apps.ecmwf.int/datasets/data/s2s). Description of the reforecast data from the two S2S models can be found in Table 1 (more details are available in Vitart et al. 2017). Variables used in this study include daily horizontal winds, specific humidity, OLR and precipitation. The different horizontal resolutions of these two S2S models are interpolated to a uniform resolution of $1.5^{\circ} \times 1.5^{\circ}$. 
The CMA model produces daily forecast, whereas the ECMWF model is initiated twice weekly (every Monday and Thursday). For a fair comparison, a data processing method developed by Yang et al. (2018) is utilized to reprocess the ECMWF's twice-weekly model outputs (104 initialization dates yearly) to daily reforecast data. The so-derived dataset contains a continuous distribution of reforecasts on all dates from 1998 to 2012, at all lead times from 3 to 42 days. In this manner, the original data array and the new data array could be consistent, and the evaluation of prediction skills will not be influenced by this special treatment (Yang et al. 2018).

\subsection{Methods}

\subsubsection{Definition of extreme rainfall}

Given that models generally have systematic biases, a relative threshold (percentile-based threshold) is used to define the observed and forecasted extreme rainfall (Jones et al. 1999; Yan et al. 2002; Zhang et al. 2011b; Li et al. 2012; Xavier et al. 2014). For a given calendar day at a grid, a rainfall extreme occurs when the daily precipitation amount exceeds a criterion of the 90th percentile of a set of daily records, including those on the same calendar day and 90 neighboring days (45 before and 45 after that day) from 1998 to 2012 (Li et al. 2017; Li et al. 2020b).

In each BSISO1 phase, the probability of extreme rainfall occurrence (Px, $\mathrm{x}$ denoting the phases $1-8$ ), is defined by the ratio of the number of extreme rainfall days to the number of total days. To quantify the influence of BSISO1 state on extreme rainfall, the probability of extreme rainfall occurrence during different BSISO1 phases relative to the non-BSISO1 period is compared. Thus, the percentage change in the probability of extreme rainfall occurrence during each of the BSISO1 
213 phases is calculated as $\left[\left(P_{X}-P_{\text {non-BSISO1 } 1}\right) / P_{\text {non-BSISO1 }} \times 100 \%\right]$, where the

$214 P_{\text {non-BSISO1 }}$ represents the probability of extreme rainfall during the non-BSISO1 215 period.

\subsubsection{Verification metrics}

For the deterministic verification metric, the bivariate anomaly correlation coefficient (ACC) of PC1 and PC2 associated with the BSISO1 is used to quantitatively evaluate the forecast skills of BSISO1 on different lead times (Lin et al. 2008). The definition of ACC is given below:

$$
\mathrm{ACC}=\frac{\sum_{\mathrm{t}=1}^{\mathrm{T}}\left[\mathrm{F}_{1 \mathrm{t}} \mathrm{0}_{1 \mathrm{t}}+\mathrm{F}_{2 \mathrm{t}} \mathrm{O}_{2 \mathrm{t}}\right]}{\left.\left.\sqrt{\sum_{\mathrm{t}=1}^{\mathrm{T}}\left[\mathrm{F}_{2 \mathrm{t}}^{2}+\mathrm{F}_{2 \mathrm{t}}^{2}\right]}\right] \sqrt{\sum_{\mathrm{t}=1}^{\mathrm{T}}\left[\mathrm{O}_{2 \mathrm{t}}^{2}+\mathrm{O}_{2 \mathrm{t}}^{2}\right.}\right]},
$$

where $\mathrm{F}$ and $\mathrm{O}$ refer to the forecasted and observed BSISO1 index, respectively. The $\mathrm{t}$ indicates time, and $\mathrm{T}$ is the total number of forecast times. The subscripts 1 and 2 denote different variables (such as PC1 and PC2). of the amplitude and phase of BSISO to ACC skill. Here, o and f refer to amplitude, and $\varphi$ and $\theta$ are phase angles in the observations and predictions, respectively. ACC in polar coordinates is then defined as Wang et al. (2019):

Because both amplitude and phase errors of BSISO may contribute to skill degradation, the observed and predicted BSISO1 index are rewrote into polar coordinates as $\mathrm{O}(\mathrm{o}, \varphi)$ and $\mathrm{F}(\mathrm{f}, \theta)$, respectively, to separate the relative contribution polar coordinates is then defined as Wang et al. (2019):

$$
\operatorname{ACC}=\frac{\sum_{\mathrm{t}=1}^{\mathrm{T}} \mathrm{f}_{\mathrm{t}} \cdot \mathrm{o}_{\mathrm{t}} \cdot \cos \left(\theta_{\mathrm{t}}-\varphi_{\mathrm{t}}\right)}{\sqrt{\sum_{\mathrm{t}=1}^{\mathrm{T}} \mathrm{f}_{\mathrm{t}}^{2}} \sqrt{\sum_{\mathrm{t}=1}^{\mathrm{T}} \mathrm{o}_{\mathrm{t}}^{2}}} .
$$
amplitude of BSISO: 


$$
\mathrm{ACC}_{\mathrm{a}}=\frac{\sum_{\mathrm{t}=1}^{\mathrm{T}} \mathrm{f}_{\mathrm{t}} \cdot \mathrm{o}_{\mathrm{t}}}{\sqrt{\sum_{\mathrm{t}=1}^{\mathrm{T}} \mathrm{f}_{\mathrm{t}}^{2}} \sqrt{\sum_{\mathrm{t}=1}^{\mathrm{T}} \mathrm{o}_{\mathrm{t}}^{2}}} .
$$

Assuming amplitude of BSISO is perfectly forecasted, i.e., the linear correlation coefficient between $f_{t}$ and $o_{t}$ is $1, \mathrm{ACC}$ is the scalar phase correlation between the forecasted and observed phases of BSISO:

$$
\operatorname{ACC}_{p}=\frac{\sum_{t=1}^{\mathrm{T}} o_{\mathrm{t}}^{2} \cdot \cos \left(\theta_{\mathrm{t}}-\varphi_{\mathrm{t}}\right)}{\sum_{\mathrm{t}=1}^{\mathrm{T}} \mathrm{o}_{\mathrm{t}}^{2}}
$$

To judge the similarity of the spatial distribution between observed and forecasted fields, the pattern correlation coefficient (PCC) is calculated. The normalized root-mean-square error (NRMSE), indicating the amplitude of forecast error, is the RMSE normalized by the observed spatial standard deviation with reference to the whole domain (Lee and Wang 2014). ACC and PCC range from -1 to 1. The closer to 1 the values of ACC and PCC are, the more skillfully the model performs. The NRMSE varies from 0 to 1 . The smaller the NRMSE is, the less biased the amplitude is.

For the probabilistic verification metric, the categorical verification score referred to as Heidke Skill Score (HSS) is used to appraise the hit rate of extreme rainfall. The HSS, which can comprehensively evaluate model performance in simulating the probability of SCER occurrence, measures the fraction of correct forecasts after eliminating the corrected forecasts that are purely due to random chance (Heidke, 1926). The HSS is written as follows:

$$
H S S=\frac{2(a d-b c)}{(a+c)(c+d)+(a+d)(b+d)}
$$

where $a$ denotes the number of observed extreme rainfall that are correctly forecasted, $b$ represents the number of forecasted extreme rainfall that do not occur, $c$ denotes the number of observed extreme rainfall that are not forecasted, and $d$ represents the number of correct rejections. The range of the HSS is $-\infty$ to 1 . A negative HSS 
indicates a forecast worse than the random forecast, while 0 means no skill, and 1 denotes a perfect forecast. rainfall over China and their forecast biases at a 14-day lead in the two S2S models. It

\section{Forecast verification of SCER and BSISO1}

\subsection{Forecast skills of climatological summer rainfall}

Figure 1 shows the observed mean and daily standard deviations of MJJA can be found that both the climatological mean and the variability of summer daily rainfall are maximized over SC (Figs. 1a and d). Overall, both the ECMWF and CMA model have good capability in predicting the spatial distributions of summer mean precipitation (Figs. 1b and c) and the daily precipitation variability (Figs. 1e and f) over China at a 14-day lead. However, the ECMWF model obviously outperforms the CMA model for the spatial distribution of both summer mean rainfall (with PCC of 0.86 vs 0.64 ) and daily standard deviations (with PCC of 0.89 vs 0.61 ) over China. For ECMWF, both summer mean rainfall and intensity of daily rainfall variability are overestimated over most regions of northwestern SC, but they are slightly underestimated over the southeast coast. The CMA presents an evident underestimation for both mean rainfall and daily variations over entire SC.

\subsection{Forecast skills of the SCER}

Consistent with the summer mean precipitation prediction results, the domainaveraged 90th percentile of precipitation predicted by ECMWF model is higher than observation, whereas the CMA model shows a smaller value (Fig. 2a). With the observed areal-mean 90th percentile of precipitation being $14.5 \mathrm{~mm} / \mathrm{d}$, the CMA forecasted thresholds range from $7.5 \mathrm{~mm} / \mathrm{d}$ to $9.5 \mathrm{~mm} / \mathrm{d}$ for different lead times. As 
for ECMWF, the forecasted threshold is around $15-17 \mathrm{~mm} / \mathrm{d}$. According to the forecasted threshold (90th percentile) of extreme rainfall in each grid at different lead times, the capability of predicting SCER occurrence by the two S2S model is then assessed.

The HSS spatial distributions in Figs. 2c-h suggest that the ECMWF model has useful skills (with HSS larger than 0.1) in predicting extreme rainfall occurrences over the majority of SC, and the useful skills can persist up to a 21-day lead along the southeast coast. In contrast, the CMA model shows lower prediction skill at a 7-day lead, as only a small part of region shows useful HSS (larger than 0.1), and no useful skills can be found at 14-day and 21-day leads. Figure $2 \mathrm{~b}$ shows that the areal mean HSS over SC drops quickly as the lead time increases in both two models, either for the predictions of individual members or of the ensemble mean. Compared to the predictions of individual members, the ensemble prediction has higher and more stable predictive skills at most lead times. Using a criterion with HSS of 0.1 (which is considered a useful forecast), the ensemble prediction of the CMA model can capture the SCER occurrence within 7 days in advance, while the ensemble prediction from the ECMWF model can effectively reproduce SCER up to a 14-day lead.

In sum, the above forecast verification reveals that the two models have limited skills beyond the lead time of 14 days in predicting the SCER occurrences, which is consistent with the subseasonal predictive level of extreme rainfall among most of the current operational models ( $\mathrm{Li}$ et al. 2019).

\subsection{Forecast skills of BSISO1 index}

Because of the significant influence of BSISO on SCER (Hsu et al. 2016), the models' capacity in capturing the BSISO1 could directly affect the prediction skill of 
SCER. Therefore, we first evaluate the prediction skill of BSISO1 indices in the two models. Here, the forecasted BSISO1 indices are obtained by projecting the forecasted normalized OLR and U850 anomalies from each S2S model onto the observed BSISO1 spatial patterns, which are consistent with the observed first two EOF modes of BSISO defined by Lee et al. (2013).

Figure 3 shows the ACC skills of BSISO1 indices with a function of lead time. For both the ECMWF and CMA models, the ACCs for the forecasted BSISO1 indices decrease with the increase of lead time. Taking $\mathrm{ACC}=0.5$ as the threshold of a valid forecast skill, the lead time of useful ensemble prediction of BSISO1 indices from ECMWF is up to 24 days, which is noticeably higher than that of CMA with the lead time of useful prediction being only up to 10 days. If the amplitude of BSISO1 is perfectly forecasted, the ECMWF (CMA) model can skillfully predict the BSISO1 indices 30 (11) days in advance, and the $\mathrm{ACC}_{\mathrm{p}}$ is always slightly higher than ACC. If the phase error of BSISO1 is ignored, $\mathrm{ACC}_{\mathrm{a}}$ of the two $\mathrm{S} 2 \mathrm{~S}$ models is above 0.85 at all lead times. This indicates that the phase error, rather than the amplitude error, matters more in the prediction skills of BSISO1 indices. Because the models always have skills in forecasting the BSISO1's intensity, whether they can skillfully predict the BSISO1 depends largely on the capacity for predicting the phase of BSISO1.

\section{Forecast verification of BSISO1's modulation on SCER}

Is the prediction skill of BSISO1 indices related to that of SCER probability as the BSISO1 strongly modulates the SCER occurrences? To address this question, we calculate the linear correlation between the ensemble prediction skills (HSSs) of BSISO1 indices and SCER occurrences at all lead times, and it is found that in both models, the HSS skills for BSISO1 indices are always significantly correlated with 
areal mean HSS skills of SCER with a correlation coefficient of 0.98 in ECMWF and 0.96 in CMA, both of which pass the $99 \%$ confidence level. The robust relationship suggests that the prediction by S2S models could reflect the strong modulation of BSISO1 on SCER probability.

As shown in Figure 4, with respect to the non-BSISO period, the observed probability of extreme rainfall increases mostly over the Yangtze River Valley (YRV) with rises of $30-80 \%$ occurring during phases $2-3$ of the BSISO1, while pronounced increases of extreme rainfall higher than 60\% appear in southeastern China at phase 4 (Fig. 4). How well do the S2S models reproduce the modulation of BSISO1 on SCER probability? As shown in Figure 4, the ECMWF model can predict the increased extreme rainfall probability over the YRV during phases 2-3 and over southeastern China in phase 4 at lead times within 14 days, although the intensity and location of maximum probability slightly depart from the observation. In phase 2 , the ECMWF model underestimates probability of extreme rainfall in the YRV, especially beyond 14-day lead times. The ECMWF model performs better in phase 3. It can skillfully predict the regions with increased probability of extreme rainfall up to a 21-day lead, with PCCs larger than 0.5. In phase 4, ECMWF underestimates the observed probability increase of extreme rainfall over southeastern China, and overestimates the probability intensity over the YRV, resulting in relatively lower PCCs than in the other two phases. It is disappointing that the CMA model shows very limited skills in predicting the spatial distributions of SCER probability in phases 2-4 of the BSISO1. Even at a 7-day lead, the forecasting underestimates the extreme rainfall probability over the YRV in phases 2-3 and over southeastern China in phase 4.

Figure 5 shows the PCC and NRMSE prediction skills for the distribution of SCER probability as a function of lead time during phases 2-4 of BSISO1. In general, 
the PCC (NRMSE) tends to decrease (increase) with the lead time. The ensemble predictions show that the ECMWF model can skillfully predict the SCER probability at a 7-day lead in phase 2, and at up to a 25-day lead in phase 3. During phases 2 and 3, the PCC skills of the CMA model are mostly lower than those of the ECMWF model, as the skills are only useful at 2-3-day lead. No prediction skills can be found in phase 4 for both two models.

Figure 6 shows the HSS distributions of SCER probability during phases 2-4 of the BSISO1. In phase 2, within 1-week lead times, the ECMWF model has HSSs over 0.2 in most areas of SC, and the areal mean HSSs over SC are above 0.1. In phase 3, ECMWF also has high HSSs over the majority of SC at 7-14-day leads, suggesting encouraging forecast skill of BSISO1's modulation on SCER probability during this phase. In phase 4, high HSSs are mainly confined to the southeast coast only at lead times within a week. For CMA, negative HSSs appear at most parts of SC in each phase, indicating the poor skill of CMA in forecasting the probability of SCER under the influence of BSISO1.

Figure 7 shows the areal mean HSSs of SCER modulated by BSISO1 with a function of lead time. It can be found that useful skills (HSS exceeds 0.1) of ensemble prediction can be obtained at lead time up to around 10 days for ECMWF, while the lead time is limited to 5 days for CMA during phases 2-3 of BSISO1. The ECMWF (CMA) model exhibits relatively low skills in phase 4, with HSSs being lower than 0.1 only beyond a 7-day (3-day) lead.

In summary, the two models have some capability to predict the probability of SCER that is modulated by BSISO1, but biases can be found in both intensity and location of SCER probability changes. In terms of the deterministic skills (PCC and NRMSE) for SCER probability, the ECMWF model displays useful skills up to 1 
week in advance in phase 2, and 25 days in advance in phase 3 . The CMA model cannot predict the BSISO1's modulation on SCER probability in phases 2-3 even at a 5-day lead. Poor skills are commonly found in phase 4, with the useful prediction skills for ECMWF can only be gained within 3-day lead times and no such skills exist for CMA. Based on probabilistic forecast verification (HSS), useful skills of SCER probability can be gained at up to around a 10-day lead during phases $2-3$, and at a 7 day lead in phase 4 for ECMWF, but the counterpart lead time is only 3 or 4 days for CMA in all three phases.

\section{Causes of the prediction biases in SCER}

Although the S2S models can reproduce the modulations of BSISO1 on SCER probability to some extent, the prediction skill is still quite limited. What are the possible causes of model biases in predicting the SCER modulated by BSISO activity? A clear answer to this question may provide some heuristic clues to improving the S2S prediction of SCER.

Because extreme rainfall is related to the favorable atmospheric circulation and abundant moisture conditions, the moisture flux divergence $-\nabla \cdot(q \vec{V})$ is considered as the main factor of SCER during BSISO1 phases (O'gorman and Schneider 2009; Hsu et al. 2016; O'Gorman et al. 2016). The moisture flux divergence $-\nabla \cdot(q \vec{V})$ could be further divided into two terms: moisture convergence $(-q \cdot \nabla \vec{V})$ and moisture advection $(-\vec{V} \cdot \nabla q)$. In this section, we will diagnose the column-integrated moisture convergence and moisture advection during phases 2-4 of BSISO1 in the observation and prediction, and further identify the possible causes for the model biases in predicting the BSISO1's modulation on SCER probabilities. 
In observation, during phases 2-3 of BSISO1 (Fig. 8, the first column), the YRV

410 is dominated by low-level southwesterly anomaly on the northwestern flank of the

411 anomalous anticyclone over the western North Pacific (WNPAC). Therefore, strong

412 moisture convergence appears over the YRV, providing a favorable condition for the

413 increase of extreme rainfall in the region (Fig. 4). As the WNPAC further propagates

414 northeastward in phase 4, the moisture divergence originally located in the southeast

415 coast diminishes, and the majority of SC witnesses a replacement by moisture

416 convergence (Fig. 8), leading to enhanced extreme rainfall over most regions south of

417 Yangtze River (Fig. 4).

418 Can the S2S models forecast the low-level WNPAC and the associated moisture

419 convergence? The horizonal patterns of the $850-\mathrm{hPa}$ wind and moisture convergence

420 forecasted at 7-, 14-, and 21-day lead are shown in Figure 8. In general, ECMWF can

421 realistically reproduce the large-scale circulation and moisture convergence during

422 phases 2-4 of BSISO1. In phase 2, because of the weaker southwesterly over the

423 northwestern flank of the WNPAC, the moisture convergence in the YRV region is

424 underestimated in the ECMWF model at a 7-day lead. At lead times beyond 14 days,

425 the WNPAC is forecasted northeastward compared with observation, leading to

426 weakened moisture convergence and therefore underestimated probability of extreme

427 rainfall over the YRV (Figs. 4 and 6). In phase 3, the moisture convergence

428 (divergence) in the YRV (southeast coast) is nicely forecasted up to 21 days in

429 advance, resulting in the high prediction skills of SCER probability in phase 3 (Figs. 4

430 and 6). In phase 4 , the moisture convergence center is predicted northward by $5^{\circ}$,

431 leading to the underestimation (overestimation) of extreme rainfall probability south

432 (north) of the Yangtze River (Fig. 4). In comparison to ECMWF, the CMA model 
cannot well reproduce the intensity and spatial patterns of moisture convergence and WNPAC.

Figure 9 shows the observed and forecasted spatial distribution of moisture advection during phases $2-4$ of the BSISO1. It is clear that the moisture advection also plays an important role in BSISO1's modulation on SCER probabilities, but in a opposite way. Negative moisture advection could suppress the SCER probabilities. In ECMWF, for phases 2-3, the negative moisture advection over SC is general forecasted, although its intensity gradually decreases with increasing lead time. For phase 4, although the low-level wind field is well captured, the negative moisture advection over SC could not be reproduced with all lead times, suggesting the low capacity of ECMWF in forecasting the spatial distribution of moisture $(\nabla q)$. In general, the ECMWF model performs much better than the CMA model, as the latter always underestimates the negative moisture advection over SC.

The PCC and NRMSE skills of ensemble prediction as a function of lead time for moisture convergence and moisture advection fields are shown in Figure 10. It is obvious that the CMA model shows much lower PCC skills in predicting the moisture convergence and advection than ECMWF, leading to the much worse prediction skills in SCER probability (Fig. 5) and areal-mean HSSs (Fig. 7) of SCER. Another notable feature is that the prediction of moisture convergence always has better skills than that of moisture advection in ECMWF, suggesting that the model still has difficulty in reproducing the spatial pattern of moisture in the region. Taking $\mathrm{PCC}=0.5$ as the threshold of useful prediction skill, the ECMWF model can predict the moisture convergence 25 days in advance in phase 2 , and beyond 30 days in phases $3-4$. For the moisture advection, useful skills can be gained up to 25 days in advance in phase 2 , and beyond 30 days in phase 3 , but only within 5 days in advance in phase 4 . It is 
noteworthy that although the moisture convergence in phase 4 shows a skill comparable to those in phases 2-3 in ECMWF, the low prediction skill of moisture advection in phase 4 results in the poor prediction skills for the probability and HSS of SCER in phase 4 (Figs. 5 and 7). The CMA model has poor skills (PCC less than 0.5) at all lead times for both moisture convergence and moisture advection, which are consistent with its low prediction skills of SCER probability (Figs. 5 and 7).

To further check whether the prediction skills of SCER probability during phases 2-4 of the BSISO1 are related to the models' performance in capturing the BSISO1related moisture convergence and advection, the scatter plots between the prediction skills (PCC) of SCER probability and column-integrated moisture convergence and moisture advection in ECMWF and CMA ensemble members at all forecast leads are shown in Figure 11. In all ensemble members from both two models, the PCC skills for moisture convergence are significantly correlated with those of the SCER probability, suggesting that the prediction errors in SCER probabilities may stem from the biases in predicting the BSISO1's modulation on the large-scale moisture convergence. On the contrary, the PCC skills of moisture advection in CMA have no relationship with the PCC skills of SCER probability, indicating that moisture advection may play a secondary role in BSISO1's modulation. Thus, the models' capability to represent the associated moisture convergence is the key to the skillful prediction of BSISO1's modulation on SCER probability. Note, however, that the relationship between PCC skills of different contributors and SCER probability also depends on the overall prediction skill of SCER probability. If the overall prediction skill is high, the PCC relationship becomes relatively weak (Fig. 11, phase 3), and verse visa (Fig. 11, phase 4). In other words, when the prediction is approaching 
perfection, the prediction skill is more sensitive to the secondary term $(-\vec{V} \cdot \nabla q)$, rather than the first contributor $(-q \cdot \nabla \vec{V})$.

\section{Conclusion and discussion}

\subsection{Conclusion}

Using the reforecast data of 1998-2012 from the CMA and ECWMF models that have been involved in the WMO S2S project, the present study investigates the prediction skills of SCER and BSISO1 activity and unravels how the prediction biases of BSISO1-related moisture processes lead to the biases in predicting the SCER probability. The main conclusions are summarized as follows:

1) Although both $S 2 S$ models can predict the spatial pattern of summer mean rainfall and the standard deviation of daily rainfall over China, the ECMWF model obviously outperforms the CMA model. For ECMWF, both summer mean rainfall and daily variation are slightly overestimated (underestimated) over the northwest (southeast) part of SC. The CMA model presents an evident underestimation for both mean rainfall and daily variation over entire SC.

2) Compared to CMA model, ECMWF model shows higher skill in reproducing the summer rainfall variability with a relatively small differences in the threshold value of SCER (the 90th percentile of rainfall amount) at all lead times against the observation. ECMWF also shows higher HSS skills of rainfall extreme occurrence within 14-day lead times over the entire SC area, and at up to 21-day lead over the southeast coast. In contrast, CMA can only perform useful HSS skills of rainfall extreme occurrence within a forecast lead time of 7 days.

3) The ensemble forecasts from ECMWF and CMA show skillful prediction for the BSISO1 indices (with ACC larger than 0.5) at 24-day and 10-day forecast lead 
times, respectively. The prediction skills of BSISO1 phase, rather than its amplitude, determine the total ACC skills of BSISO1 index, suggesting that elimination of phase errors could improve the prediction skills of BSISO1.

4) Given that the probabilistic prediction skill (HSS) of SCER occurrence corresponds well to the deterministic prediction skill (ACC) of BSISO1 indices, how the SCER prediction is modulated by the predicted BSISO1 is further revealed. The diagnostic results suggest that the prediction skills of moisture convergence and advection play an important role in the prediction skills of SCER probability influenced by BSISO1. The correlation analysis between the PCC skills of SCER and moisture convergence/advection reveals that moisture convergence is the first contributor to the prediction skill of SCER. Note, however, that, as the secondary contributor, moisture advection may exert a "buckets effect", as revealed by its good relationship with PCC of SCER during phase 4 of BSISO1 but with the lowest prediction skill of SCER, implying that it is also quite important in predicting the SCER modulated by the BSISO.

\subsection{Discussion}

The above results suggest that improving models' capability of predicting BSISO is crucial for enhancing model performance in prediction of SCER. Specifically, the SCER prediction skill largely depends on whether the models can correctly reproduce the BSISO-related moisture convergence and advection. Thus, one strategy to promote the prediction skill of SCER is to improve models' capability in predicting BSISO-related moisture processes, which could be achieved by adjusting/improving the convection parameterization schemes (Kim et al. 2014; Jiang et al. 2015; Yang et al. 2021b). Improvements of additional factors such as the data assimilation schemes 
(Liu et al. 2021), initialization (Orsolini et al. 2013; Bo et al. 2020), and ocean-landatmosphere coupling techniques (Ford et al. 2018) of the models may also helpful to increase the forecast skill of BSISO and related moisture processes and thus the SCER prediction skill. However, the S2S datasets provide reforecast from models with various physics and parameterizations. It is difficult to identify the key parameters controlling the BSISO moisture processes and thus the SCER prediction skill by comparing the reforecast data from models with different configurations. Performing model experiments based on the same model would be needed and it is our future study.

Considering the robust relationship between the SCER probability and BSISO, before a further advance in dynamical models is achieved, a dynamical-statistical hybrid method could be an effective way to improve the subseasonal prediction skill for extreme rainfall (Ren et al. 2014; Guo et al. 2017).

While the present study shows the evident effects of model biases in BSISO1 on the prediction skill of SCER. Whether and the extent to which the model skill in BSISO2 (quasi-biweekly oscillation) exerts impacts on the SCER prediction merit further exploration.

\section{Acknowledgments}

This work was supported by the National Key R\&D Program of China (Grant Nos: 2018YFC1505905), and the National Natural Science Foundation of China (Grant Nos: $42088101 \& 41805048)$.

\section{References}


Annamalai H, Slingo JM (2001) Active/break cycles: diagnosis of the intraseasonal variability of the Asian Summer Monsoon. Clim Dyn 18(1): 85-102. doi:10.1007/s003820100161.

Bo Z, Liu X, Gu W, Huang A, Fang Y, Wu T, Jie W, Li Q (2020) Impacts of atmospheric and oceanic initial conditions on boreal summer intraseasonal oscillation forecast in the BCC model. Theor Appl Climatol 142(1): 393-406. doi:10.1007/s00704-020-03312-2.

Brunet G, Shapiro M, Hoskins B, Moncrieff M, Dole R, Kiladis GN, Kirtman B, Lorenc A, Mills B, Morss R et al (2010) Collaboration of the Weather and Climate Communities to Advance Subseasonal-to-Seasonal Prediction. Bull Amer Meteorol 91(10): 1397-1406. doi:10.1175/2010bams3013.1.

Chen T, Chen J (1993) The 10-20-Day Mode of the 1979 Indian Monsoon: Its Relation with the Time Variation of Monsoon Rainfall. Mon Weather Rev 121(9): 2465-2482. doi:10.1175/1520-0493(1993)121<2465:Tdmoti>2.0.Co;2.

Chen T, Chen J (1995) An Observational Study of the South China Sea Monsoon during the 1979 Summer: Onset and Life Cycle. Mon Weather Rev 123(8): 2295-2318. doi:10.1175/15200493(1995)123<2295:Aosots>2.0.Co;2.

Chen Y, Zhai P (2017) Simultaneous modulations of precipitation and temperature extremes in Southern parts of China by the boreal summer intraseasonal oscillation. Clim Dyn 49(9): 3363-3381. doi:10.1007/s00382-016-3518-4

de Andrade FM, Coelho CAS, Cavalcanti IFA (2019) Global precipitation hindcast quality assessment of the Subseasonal to Seasonal (S2S) prediction project models. Clim Dyn 52(9): 5451-5475. doi:10.1007/s00382-018-4457-z.

Dee DP, Uppala SM, Simmons AJ, Berrisford P, Poli P, Kobayashi S, Andrae U, Balmaseda MA, Balsamo G, Bauer $P$ et al (2011) The ERA-Interim reanalysis: configuration and performance of the data assimilation system. Q J R Meteorol Soc 137: 553. doi:10.1002/qj.828.

Ding R, Li J, Seo KH (2011) Estimate of the predictability of boreal summer and winter intraseasonal oscillations from observations. Mon Weather Rev 139:2421-2438

Fang Y, Li B, Liu X (2019) Predictability and Prediction Skill of the Boreal Summer IntraSeasonal Oscillation in BCC_CSM Model. J Meteorol Soc Japan 97. doi:10.2151/jmsj.2019019.

Ford TW, Dirmeyer PA, Benson DO (2018) Evaluation of heat wave forecasts seamlessly across subseasonal timescales. Clim Atmos Sci 1(1): 20. doi:10.1038/s41612-018-0027-7.

Fu X, Lee JY, Wang B, Wang W, Vitart F. 2013. Intraseasonal forecasting of the Asian summer monsoon in four operational and research models. J Clim 26: 4186-4203.

Guo Q, Liu X, Wu T, Cheng B, Li R, Wei L (2017) Verification and correction of EastChina summer rainfall prediction based on BCC_CSM model. Chin J Atmos Sci 41 (1): 71-90. doi:10.3878/j.issn.1006-9895.1602.15280. 
He Z, Hsu PC, Liu X, Wu T, Gao Y (2019) Factors Limiting the Forecast Skill of the Boreal Summer Intraseasonal Oscillation in a Subseasonal-to-Seasonal Model. Adv Atmos Sci 36(1): 104-118. doi:10.1007/s00376-018-7242-3.

Heidke P (1926) Berechnung des Erfolges und der Güte der Windstärkevorhersagen im Sturmwarnungsdienst. Geogr Ann 8: 301-349. doi:10.2307/519729.

Hsu PC, Fu Z, Murakami H, Lee J-Y, Yoo C, Johnson NC, Chang CH, Liu Y (2021) East Antarctic cooling induced by decadal changes in Madden-Julian oscillation during austral summer. Sci Adv 7(26). doi:10.1126/sciadv.abf9903.

Hsu PC, Lee JY, Ha KJ (2016) Influence of boreal summer intraseasonal oscillation on extreme rainfall in southern China. Int J Climatol 36: 1403. doi:10.1002/joc.4433.

Hsu PC, Lee JY, Ha KJ, Tsou CH (2017) Influences of Boreal Summer Intraseasonal Oscillation on Heat Waves in Monsoon Asia. J Clim 30(18): 7191-7211. doi:10.1175/jcli-d-16-0505.1.

Hu W, Duan A, He B (2017) Evaluation of intra-seasonal oscillation simulations in IPCC AR5 coupled GCMs associated with the Asian summer monsoon. Int J Climatol 37:476-496

Ji Y, Sun X, Xu Y, Yao J, Yang XQ (2021) Summer Regional Pentad Extreme Precipitation in Eastern China and Their Possible Causes. Front Earth Sci 8(612). doi:10.3389/feart.2020.598025.

Jiang X, Waliser DE, Xavier PK, Petch J, Klingaman NP, Woolnough SJ, Guan B, Bellon G, Crueger T, DeMott C et al (2015) Vertical structure and physical processes of the MaddenJulian oscillation: Exploring key model physics in climate simulations. J Geophys Res Atmos 120(10): 4718-4748. doi:10.1002/2014JD022375.

Jie W, Vitart F, Wu T, Liu X (2017) Simulations of Asian Summer Monsoon in the Sub-seasonal to Seasonal Prediction Project (S2S) database. Q J R Meteorol Soc 143(706): 2282-2295.

Jones PD, Horton EB, Folland CK, Hulme M, Parker DE, Basnett TA (1999) The Use of Indices to Identify Changes in Climatic Extremes. Clim Change 42(1): 131-149. doi:10.1023/A:1005468316392.

Kim HM, Webster PJ, Toma VE, Kim D (2014) Predictability and Prediction Skill of the MJO in Two Operational Forecasting Systems. J Clim 27(14): 5364-5378. doi:10.1175/jcli-d-1300480.1 .

Lau W, Yang G, Shen S (1988) Seasonal and Intraseasonal Climatology of Summer Monsoon Rainfall over Eeat Asia. Mon Weather Rev 116. doi:10.1175/15200493(1988)116<0018:SAICOS>2.0.CO;2.

Lee JY, Wang B (2014) Future change of global monsoon in the CMIP5. Clim Dyn 42: 101. doi:10.1007/s00382-012-1564-0.

Lee JY, Wang B, Wheeler MC, Fu X, Waliser DE, Kang IS (2013) Real-time multivariate indices for the boreal summer intraseasonal oscillation over the Asian summer monsoon region. Clim Dyn 40(1): 493-509. doi:10.1007/s00382-012-1544-4. 
Lee SS, Moon JY, Wang B, Kim HJ (2017) Subseasonal Prediction of Extreme Precipitation over Asia: Boreal Summer Intraseasonal Oscillation Perspective. J Clim 30(8): 2849-2865. doi:10.1175/jcli-d-16-0206.1.

Lee SS, Wang B (2016) Regional boreal summer intraseasonal oscillation over Indian Ocean and Western Pacific: comparison and predictability study. Clim Dyn 46(7): 2213-2229. doi:10.1007/s00382-015-2698-7.

Lee SS, Wang B, Waliser DE, Neena JM, Lee JY (2015) Predictability and prediction skill of the boreal summer intraseasonal oscillation in the Intraseasonal Variability Hindcast Experiment. Clim Dyn 45:2123-2135

Li J, Dong W, Yan Z (2012) Changes of climate extremes of temperature and precipitation in summer in eastern China associated with changes in atmospheric circulation in East Asia during 1960-2008. Chin Sci Bull 57: 1856-1861.

Li J, Liu B, Mao J (2021) Climatological intraseasonal oscillation in the middle-upper troposphere and its effect on the northward migration of the East Asian westerly jet and rain belt over eastern China. Int J Climatol 41(10): 5084-5099. doi:10.1002/joc.7118.

Li J, Wang B (2018) Predictability of summer extreme precipitation days over eastern China. Clim Dyn 51(11): 4543-4554. doi:10.1007/s00382-017-3848-x.

Li J, Wang B, Yang YM (2020a) Diagnostic Metrics for Evaluating Model Simulations of the East Asian Monsoon. J Clim 33(5): 1777-1801. doi:10.1175/jcli-d-18-0808.1.

Li J, Yan H, Zhu Z (2020b) Quantitative Analysis of Changes of Summer Extremes Temperature and Precipitation Days over China with Respect to the Mean Temperature Increase. Chin Plateau Meteor 39(3): 532-542. doi:10.7522/j.issn.1000-0534.2019.00042.

Li J, Zhu Z, Dong W (2017) Assessing the uncertainty of CESM-LE in simulating the trends of mean and extreme temperature and precipitation over China. Int J Climatol 37(4): 2101-2110. doi:10.1002/joc.4837.

Li W, Chen J, Li L, Chen H, Liu BY, Xu CY, Li XQ (2019) Evaluation and Bias Correction of S2S Precipitation for Hydrological Extremes. J Hydrometeorol 20(9): 1887-1906. doi:10.1175/jhm-d-19-0042.1.

Liang P, Lin H (2018) Sub-seasonal prediction over East Asia during boreal summer using the ECCC monthly forecasting system. Clim Dyn 50(3): 1007-1022. doi:10.1007/s00382-0173658-1.

Lin H, Brunet G, Derome J (2008) Forecast Skill of the Madden-Julian Oscillation in Two Canadian Atmospheric Models. Mon Weather Rev 136: 4130. doi:10.1175/2008mwr2459.1.

Liu B, Yan Y, Zhu C, Ma S, Li J (2020a) Record-Breaking Meiyu Rainfall Around the Yangtze River in 2020 Regulated by the Subseasonal Phase Transition of the North Atlantic Oscillation. Geophys Res Lett 47(22): e2020GL090342. doi:10.1029/2020GL090342. 
Liu B, Zhu C (2021) Subseasonal-to-Seasonal Predictability of Onset Dates of South China Sea Summer Monsoon: A Perspective of Meridional Temperature Gradient. J Clim 34(13): 56015616. doi:10.1175/jcli-d-20-0696.1.

Liu F, Ouyang Y, Wang B, Yang J, Ling J, Hsu PC (2020b) Seasonal evolution of the intraseasonal variability of China summer precipitation. Clim Dyn 54(11): 4641-4655. doi:10.1007/s00382-020-05251-0.

Liu H, Zhang DL, Wang B (2008) Daily to submonthly weather and climate characteristics of the summer 1998 extreme rainfall over the Yangtze River Basin. J Geophys Res Atmos 113(D22). doi:10.1029/2008JD010072.

Loriaux JM, Lenderink G, Siebesma AP (2016) Peak precipitation intensity in relation to atmospheric conditions and large-scale forcing at midlatitudes. J Geophys Res Atmos 121(10): 5471-5487. doi:10.1002/2015JD024274.

Madden R (1986) Seasonal Variations of the 40-50 Day Oscillation in the Tropics. J Atmos Sci 43: 3138-3158. doi:10.1175/1520-0469(1986)043<3138:SVOTDO>2.0.CO;2.

Matthews AJ (2004) Intraseasonal Variability over Tropical Africa during Northern Summer. J Clim 17(12): 2427-2440. doi:10.1175/1520-0442(2004)017<2427:Ivotad>2.0.Co;2.

Moon JY, Wang B, Ha KJ, Lee JY (2013) Teleconnections associated with Northern Hemisphere summer monsoon intraseasonal oscillation. Clim Dyn 40(11): 2761-2774. doi:10.1007/s00382-012-1394-0.

O'Gorman PA, Schneider T (2009) The physical basis for increases in precipitation extremes in simulations of 21st-century climate change. Proc Natl Acad Sci USA 106(35):14773-7. doi: 10.1073/pnas.0907610106.

Orsolini YJ, Senan R, Balsamo G, Doblas-Reyes FJ, Vitart F, Weisheimer A, Carrasco A, Benestad RE (2013) Impact of snow initialization on sub-seasonal forecasts. Clim Dyn 41(7): 1969-1982. doi:10.1007/s00382-013-1782-0.

Pegion K, Kirtman BP, Becker E, Collins DC, LaJoie E, Burgman R, Bell R, DelSole T, Min D, Zhu Y et al (2019) The Subseasonal Experiment (SubX): A Multimodel Subseasonal Prediction Experiment. Bull Am Meteorol Soc 100(10): 2043-2060. doi:10.1175/bams-d-180270.1 .

Ren HL, Liu Y, Jin FF, Yan YP, Liu XW (2014) Application of the Analogue-Based Correction of Errors Method in ENSO Prediction. Atmos Ocean Sci Lett 7(2): 157-161. doi:10.3878/j.issn.1674-2834.13.0080.

Stan C, Straus DM, Frederiksen JS, Lin H, Maloney ED, Schumacher C (2017) Review of Tropical-Extratropical Teleconnections on Intraseasonal Time Scales. Rev Geophys 55(4): 902-937. doi:10.1002/2016RG000538.

Vitart F, Ardilouze C, Bonet A, Brookshaw A, Chen M, Codorean C, Déqué M, Ferranti L, Fucile E, Fuentes M et al (2017) The Subseasonal to Seasonal (S2S) Prediction Project Database. Bull Am Meteorol Soc 98(1): 163-176. doi:10.2307/26243670. 
Wang J, Yang J, Ren HL, Li J, Bao Q, Gao M (2021) Dynamical and Machine Learning Hybrid Seasonal Prediction of Summer Rainfall in China. J Meteorol 35(4): 583-593. doi:10.1007/s13351-021-0185-0.

Wang S, Sobel AH, Tippett MK, Vitart F (2019) Prediction and predictability of tropical intraseasonal convection: seasonal dependence and the Maritime Continent prediction barrier. Clim Dyn 52(9): 6015-6031. doi:10.1007/s00382-018-4492-9.

Wang T, Chu C, Sun X, Li T (2020) Improving Real-Time Forecast of Intraseasonal Variabilities of Indian Summer Monsoon Precipitation in an Empirical Scheme. Front Earth Sci 8(408). doi:10.3389/feart.2020.577311.

Webster PJ, Magaña VO, Palmer TN, Shukla J, Tomas RA, Yanai M, Yasunari T (1998) Monsoons: Processes, predictability, and the prospects for prediction. J Geophys Res-Oceans 103(C7): 14451-14510. doi:10.1029/97JC02719.

Wheeler MC, Hendon HH (2004) An All-Season Real-Time Multivariate MJO Index: Development of an Index for Monitoring and Prediction. Mon Weather Rev 132(8): 19171932. doi:10.1175/1520-0493(2004)132<1917:Aarmmi>2.0.Co;2.

Wu J, Gao XJ (2013) A gridded daily observation dataset over China region and comparison with the other datasets. Chin J Geophys 56(4): 1102-1111. doi: 10.6038/cjg20130406.

Xavier P, Rahmat R, Cheong WK, Wallace E (2014) Influence of Madden-Julian Oscillation on Southeast Asia extreme rainfall: Observations and predictability. Geophys Res Lett 41(12): 4406-4412. doi:10.1002/2014GL060241.

Yan Z, Jones PD, Davies TD, Moberg A, Bergström H, Camuffo D, Cocheo C, Maugeri M, Demarée GR, Verhoeve T et al (2002) Trends of Extreme Temperatures in Europe and China Based on Daily Observations. Clim Change 53(1): 355-392. doi:10.1023/A:1014939413284.

Yang J, He S, Bao Q (2021a) Convective/Large-scale Rainfall Partitions of Tropical Heavy Precipitation in CMIP6 Atmospheric Models. Adv Atmos Sci 38(6): 1020-1027. doi:10.1007/s00376-021-0238-4.

Yang J, Zhu T, Gao M, Lin H, Wang B, Bao Q (2018) Late-July Barrier for Subseasonal Forecast of Summer Daily Maximum Temperature Over Yangtze River Basin. Geophys Res Lett 45(22): 12,610-612,615. doi:10.1029/2018GL080963.

Yang YM, Cho JA, Moon JY, Kim KY Wang B (2021b) Improved boreal summer intraseasonal oscillation simulations over the Indian Ocean by modifying moist parameterizations in climate models. Clim Dyn doi:10.1007/s00382-021-05822-9.

Yao J, Sun X, Tang J, Ji Y, Xu Y, Yang XQ (2020) Summer Regional Pentad Heat Wave in Eastern China and Their Possible Causes. Front Earth Sci 8(511). doi:10.3389/feart.2020.598027.

Yatagai A, Kamiguchi K, Arakawa O, Hamada A, Yasutomi N, Kitoh A (2012) APHRODITE: Constructing a Long-Term Daily Gridded Precipitation Dataset for Asia Based on a Dense 

00122.1 .

Zhang C (2005) Madden-Julian Oscillation. Rev Geophys 43(2). doi:10.1029/2004RG000158.

Zhang KY, Li J, Zhu ZW, Li T (2021) Subseasonal prediction skill of the persistent snowstorm event over southern China during early 2008 in ECMWF and CMA S2S prediction models. Adv Atmos Sci doi: 10.1007/s00376-021-0402-x.

Zhang X, Alexander L, Hegerl GC, Jones P, Tank AK, Peterson TC, Trewin B, Zwiers FW (2011b) Indices for monitoring changes in extremes based on daily temperature and precipitation data. WIREs Clim Change 2(6): 851-870. doi:10.1002/wcc.147.

750

Zhu X, Liu X, Huang A, Zhou Y, Wu Y, Fu Z (2021) Impact of the observed SST frequency in the model initialization on the BSISO prediction. Clim Dyn 57(3): 1097-1117. doi:10.1007/s00382-021-05761-5.

753

754 
Table Captions:

Table 1. Description of the reforecast data of CMA and ECMWF models.

\section{Figure Captions:}

Figure 1. Distribution of (a) climatological summer mean precipitation during 19982012 over mainland China (units: $\mathrm{mm} \mathrm{day}^{-1}$ ) and the biases (prediction minus observation) at a 14-day lead from the ensemble mean prediction of (b) the ECMWF and (c) CMA models. (d)-(f) are same as (a)-(c), except for the daily precipitation standard deviations in MJJA (units: $\mathrm{mm} \mathrm{day}^{-1}$ ). The PCC and NRMSE skills are calculated over the whole China and given in the bottom-left of each panel. The green boxes delineate the region of southern China $\left(\mathrm{SC} ; 18^{\circ}-32.5^{\circ} \mathrm{N}, 105^{\circ}-122^{\circ} \mathrm{E}\right)$.

Figure 2. (a) The observed (grey dashed line) and forecasted (colored curves) arealmean 90th percentile of rainfall (units: $\mathrm{mm} \mathrm{day}^{-1}$ ) over southern China during the summers of 1998-2012 at 5-30-day leads. The blue (red) curve represents the ensemble mean prediction from the ECMWF (CMA) model, along with the intermember spreads shown by whiskers. (b) Areal-mean Heidke Skill Score (HSS) of SCER occurrence for ensemble mean predictions from ECMWF (blue curve) and CMA (red curve) and their individual members (dashed curves) as a function of forecast lead time (in day). Distribution of HSSs for the forecasted SCER occurrence at 7-, 14-, and 21-day lead for the ensemble mean prediction from (c-e) ECMWF and (f-h) CMA models.

Figure 3. Bivariate Anomaly Correlation Coefficient (ACC) for the forecasted BSISO1 indices from the CMA (red solid curve) and ECMWF (blue solid curve) models during summers of 1998-2012 as a function of forecast lead time (in day). The long and short dashed curves represent the ACC with the assumption of perfect phase (ACCa) and perfect amplitude (ACCp) prediction, respectively.

Figure 4. Percentage changes $(\%)$ in probability of SCER during phase 2 (upper two rows), phase 3 (middle two rows), and phase 4 (bottom two rows) of BSISO1 with respect to the non-BSISO1 period. Panels from left to right are the observation, 7-, 14- and 21-day lead of ensemble predictions, respectively. The PCC skills are shown 
in the bottom of each panel. Changes exceeding the $95 \%$ confidence level are dotted.

Figure 5. The PCC skills for the percentage changes in SCER probability in (a) phase 2, (b) phase 3 and (c) phase 4 of BSISO1 with respect to the non-BSISO1 period as a function of forecast lead time (in day). The red (blue) curves represent the ensemble mean prediction from the CMA (ECMWF) models, along with inter-member spreads shown by shadings. (d-f) are some as (a-c), but for the NRMSE skills.

Figure 6. Heidke skill score (HSS, shading) of SCER for phase 2 (upper two rows), phase 3 (middle two rows), and phase 4 (bottom two rows) of BSISO1 with respect to the non-BSISO1 period. Panels from left to right are 7-, 14- and 21- lead from ensemble mean predictions, respectively. Areal mean HSS over SC is shown in the

Figure 7. As in Fig. 5 but for the areal-mean HSS.

Figure 8. Composites of column-integrated moisture convergence (shading, unit: $10^{-5} \mathrm{~m} \mathrm{~s}^{-2}$ ) and $850-\mathrm{hPa}$ wind field (vector, unit: $\mathrm{m} \mathrm{s}^{-1}$ ) anomalies for phases 2 (upper two rows), 3 (middle two rows), and 4 (bottom two rows) of the BSISO1. Panels from left to right are the observation, 7-day, 14-day and 21-day lead of ensemble mean predictions, respectively. Only the fields exceeding the 95\% confidence level are shown. Letter "A" represents the center of the anticyclonic anomaly. The case number for phase composite is shown in the upper-left corner of each panel.

Figure 10. The PCC skills for the forecasted column-integrated moisture convergence (solid curves) and moisture advection (dashed curves) from ensemble predictions of CMA (red) and ECMWF (blue) in (a) phase 2, (b) phase 3 and (c) phase 4 of BSISO1 as a function of forecast lead time (in day). (d-f) are some as (a-c), but for the NRMSE skills. To quantitatively examine whether the models can correctly predict the moisture field in critical areas, the PCCs and NRMSEs are only calculated over the region with statistically significant signals in observation. 
824 Figure 11. Scatter diagrams for PCC skills of the percentage changes in SCER 825 probability (y-axis) against the column-integrated moisture convergence (x-axis) over 826 the WNP in (a) phase 2, (b) phase 3 and (c) phase 4 of the BSISO1 for all individual 827 members at all forecast lead times from the two models. (d-f) as in (a-c), but Y axis 828 represents PCC skills of column-integrated moisture advection. The linear fit curves 829 for ECMWF (308 blue dots) and CMA (120 orange dots) are in blue and red, and the 830 large blue and red dots are the averaged PCC for ECMWF and CMA, respectively. 831 The correlation coefficients (R) between PCC skills of percentage changes in SCER 832 probability and those of are column-integrated moisture convergence are given in 833 each panel, and asterisks indicate the $\mathrm{R}$ is significant at the $95 \%$ confidence level. 
Table 1. Description of the reforecast data of CMA and ECMWF models.

\begin{tabular}{cccccc}
\hline Model & $\begin{array}{c}\text { Time } \\
\text { range }\end{array}$ & Model resolutions & $\begin{array}{c}\text { Reforecast } \\
\text { frequency }\end{array}$ & Period & $\begin{array}{c}\text { Ensemble } \\
\text { size }\end{array}$ \\
\hline CMA & 0-60d & T106, L40 & Daily & $1995-2014$ & 4 \\
ECMWF & 0-46d & Tco639/Tco319, L91 & 2/week & $1997-2016$ & 11 \\
\hline
\end{tabular}

859

860

861

862

863

864

865

866

867

868

869

870

871

872

873

874

875

876

877 
(a) OBS mean

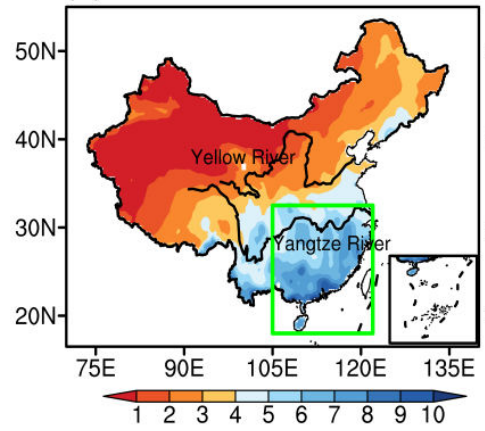

(d) OBS STD

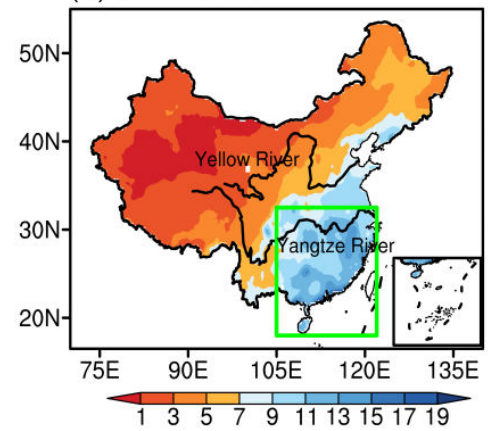

(b) ECMWF mean-diff

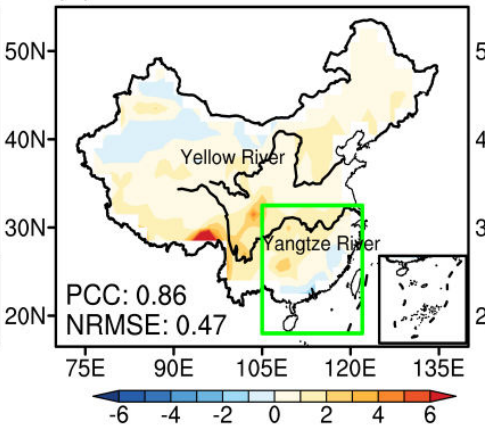

(e) ECMWF STD-diff

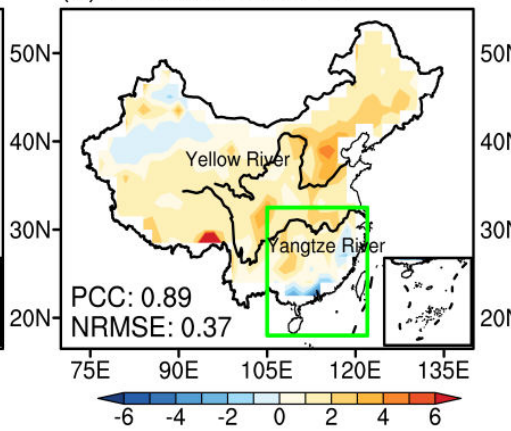

(c) CMA mean-diff

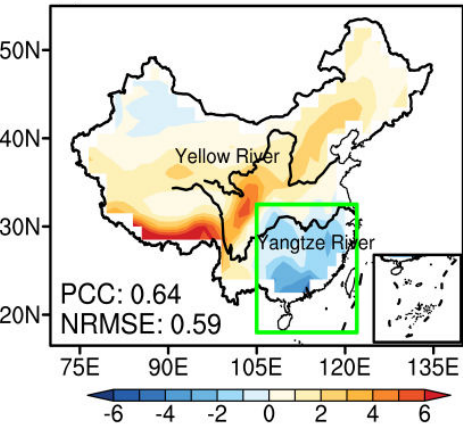

(f) CMA STD-diff

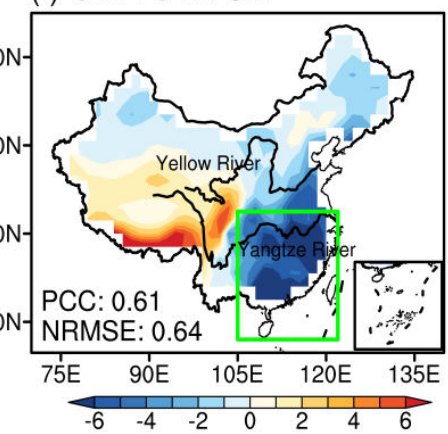

Figure 1. Distribution of (a) climatological summer mean precipitation during 19982012 over mainland China (units: $\mathrm{mm} \mathrm{day}^{-1}$ ) and the biases (prediction minus observation) at a 14-day lead from the ensemble mean prediction of (b) the ECMWF and (c) CMA models. (d)-(f) are same as (a)-(c), except for the daily precipitation standard deviations in MJJA (units: $\mathrm{mm} \mathrm{day}^{-1}$ ). The PCC and NRMSE skills are calculated over the whole China and given in the bottom-left of each panel. The green boxes delineate the region of southern China $\left(\mathrm{SC} ; 18^{\circ}-32.5^{\circ} \mathrm{N}, 105^{\circ}-122^{\circ} \mathrm{E}\right)$. 
(a) Thresholds

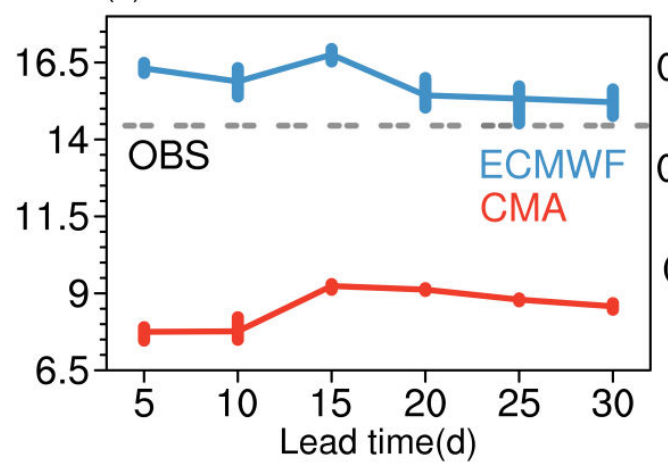

(c) Lead 7d

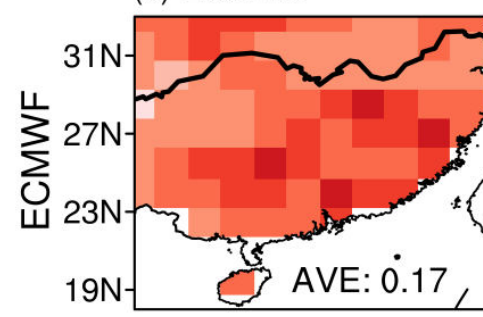

(f) Lead 7d (d) Lead 14d

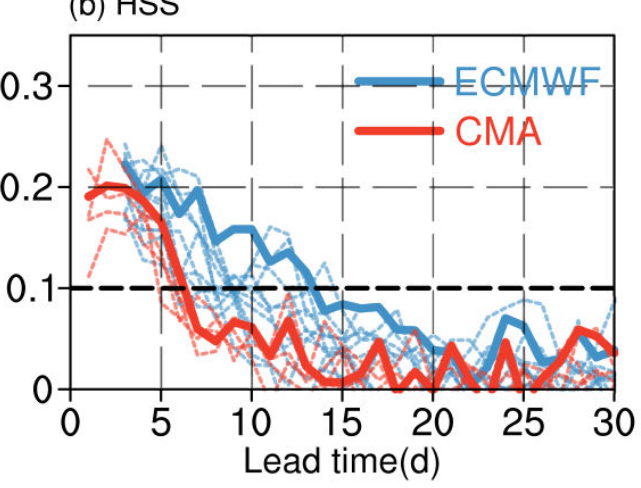

898

899

900

901

902

903

904

905

906

907

908

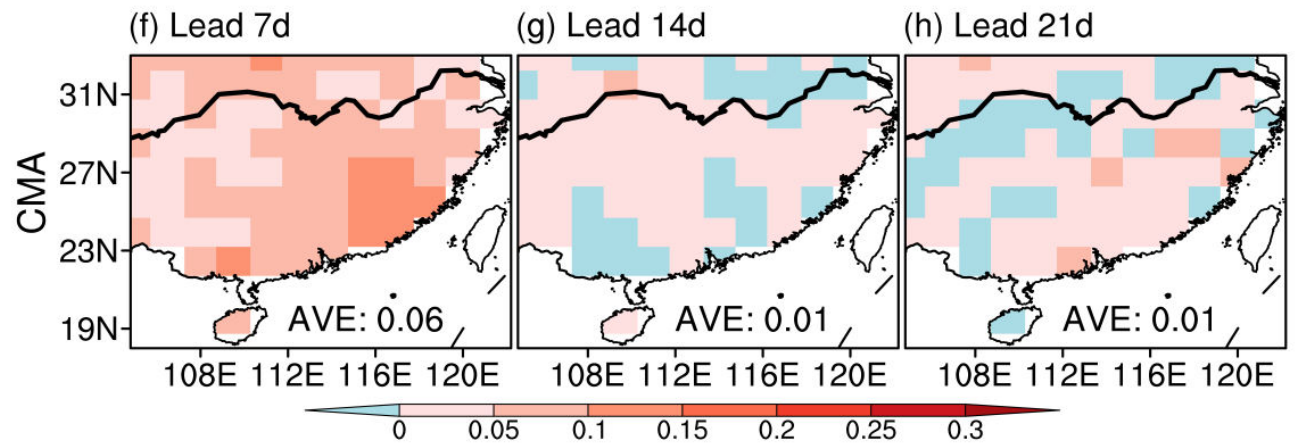

Figure 2. (a) The observed (grey dashed line) and forecasted (colored curves) arealmean 90th percentile of rainfall (units: $\mathrm{mm} \mathrm{day}^{-1}$ ) over southern China during the summers of 1998-2012 at 5-30-day leads. The blue (red) curve represents the ensemble mean prediction from the ECMWF (CMA) model, along with the intermember spreads shown by whiskers. (b) Areal-mean Heidke Skill Score (HSS) of SCER occurrence for ensemble mean predictions from ECMWF (blue curve) and CMA (red curve) and their individual members (dashed curves) as a function of forecast lead time (in day). Distribution of HSSs for the forecasted SCER occurrence at 7-, 14-, and 21-day lead for the ensemble mean prediction from (c-e) ECMWF and (f-h) CMA models. 


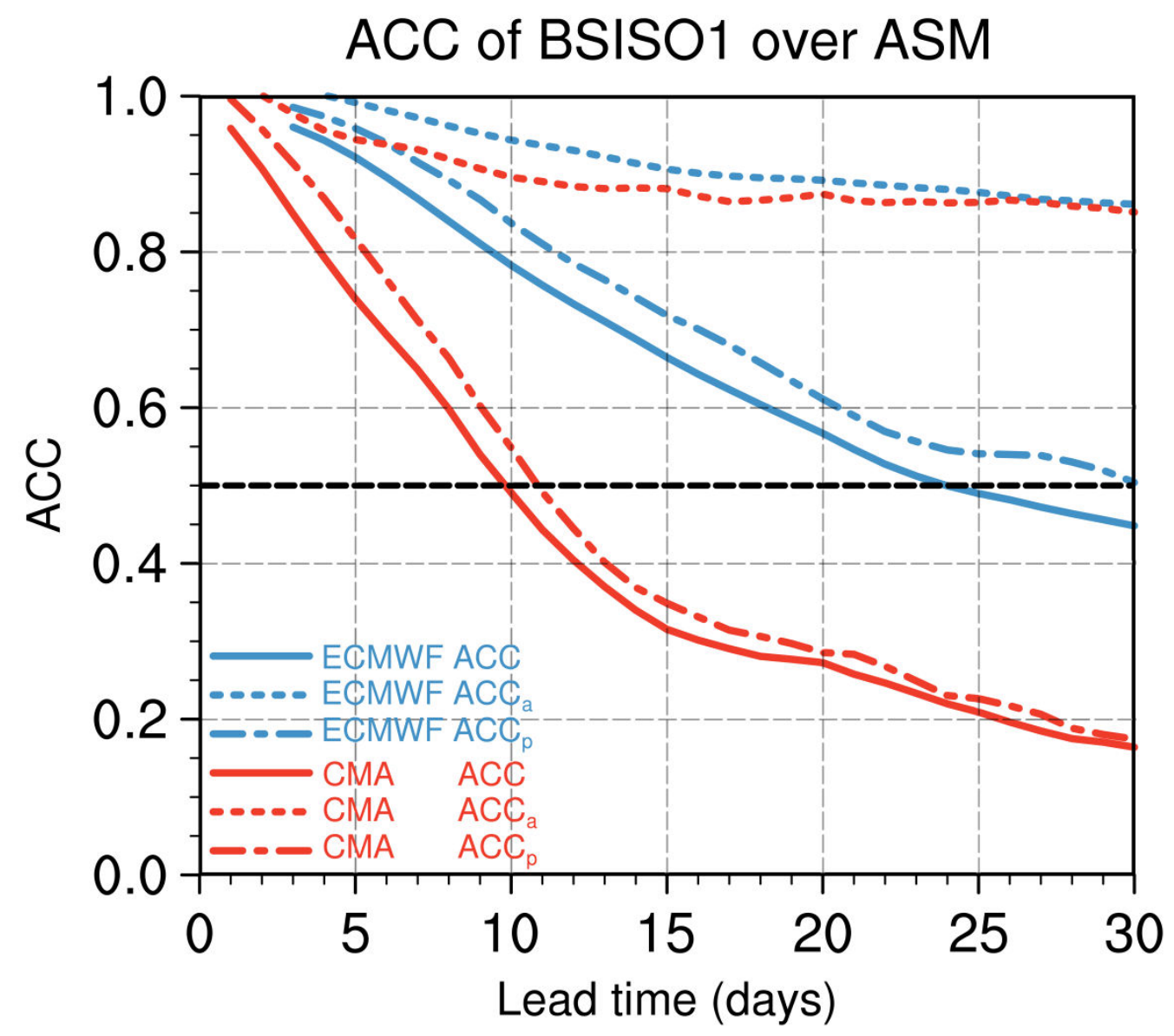

Figure 3. Bivariate Anomaly Correlation Coefficient (ACC) for the forecasted BSISO1 indices from the CMA (red solid curve) and ECMWF (blue solid curve)

912 models during summers of 1998-2012 as a function of forecast lead time (in day).

913 The long and short dashed curves represent the ACC with the assumption of perfect

914 phase (ACCa) and perfect amplitude (ACCp) prediction, respectively. 


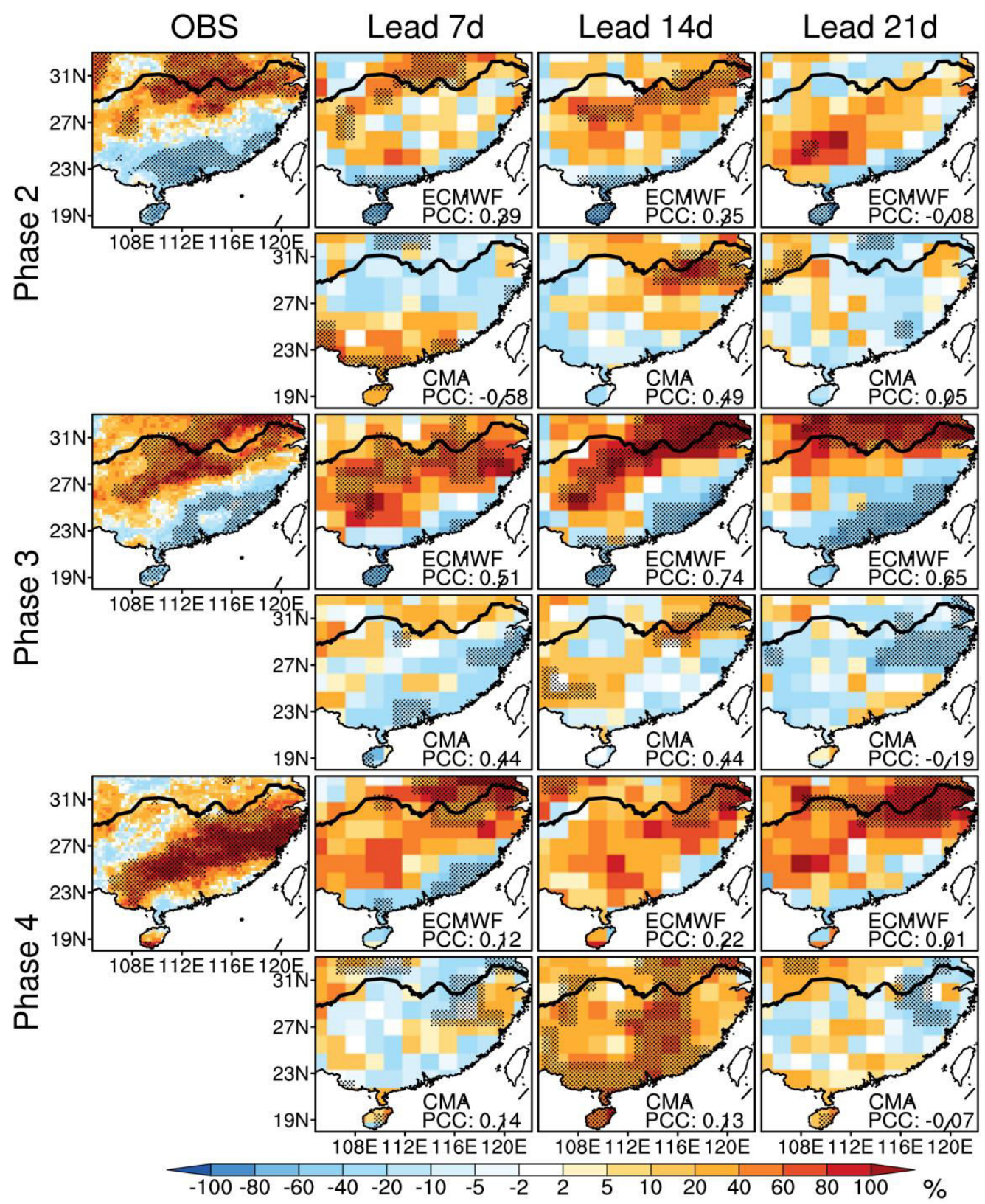

924 Figure 4. Percentage changes $(\%)$ in probability of SCER during phase 2 (upper two 925 rows), phase 3 (middle two rows), and phase 4 (bottom two rows) of BSISO1 with 926 respect to the non-BSISO1 period. Panels from left to right are the observation, 7-, 927 14- and 21-day lead of ensemble predictions, respectively. The PCC skills are shown 928 in the bottom of each panel. Changes exceeding the $95 \%$ confidence level are dotted. 
(a) Phase 2

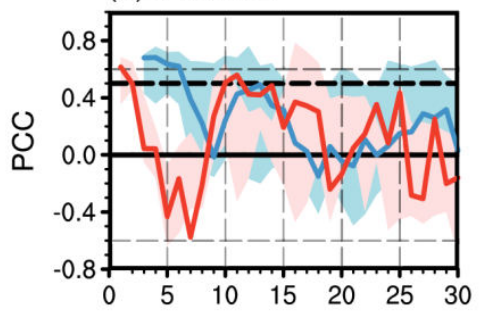

(d) Phase 2

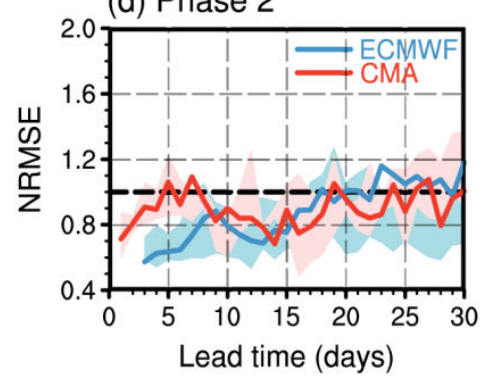

(b) Phase 3

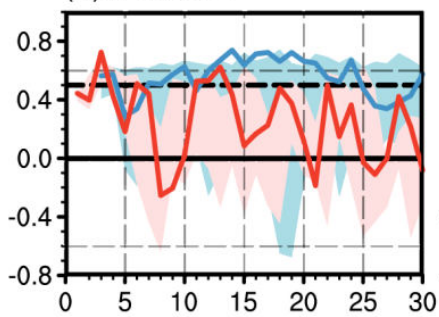

(e) Phase 3

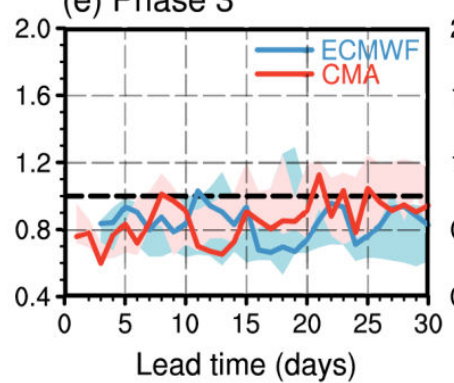

(c) Phase 4
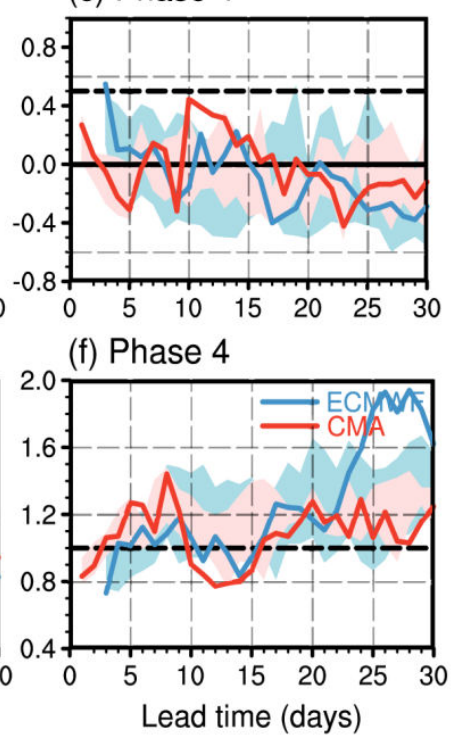

929

930

931

932

933

934

935

936

937

938

939

940

941

942

943

944

945

946

Figure 5. The PCC skills for the percentage changes in SCER probability in (a) phase 2, (b) phase 3 and (c) phase 4 of BSISO1 with respect to the non-BSISO1 period as a function of forecast lead time (in day). The red (blue) curves represent the ensemble mean prediction from the CMA (ECMWF) models, along with inter-member spreads shown by shadings. (d-f) are some as (a-c), but for the NRMSE skills. 

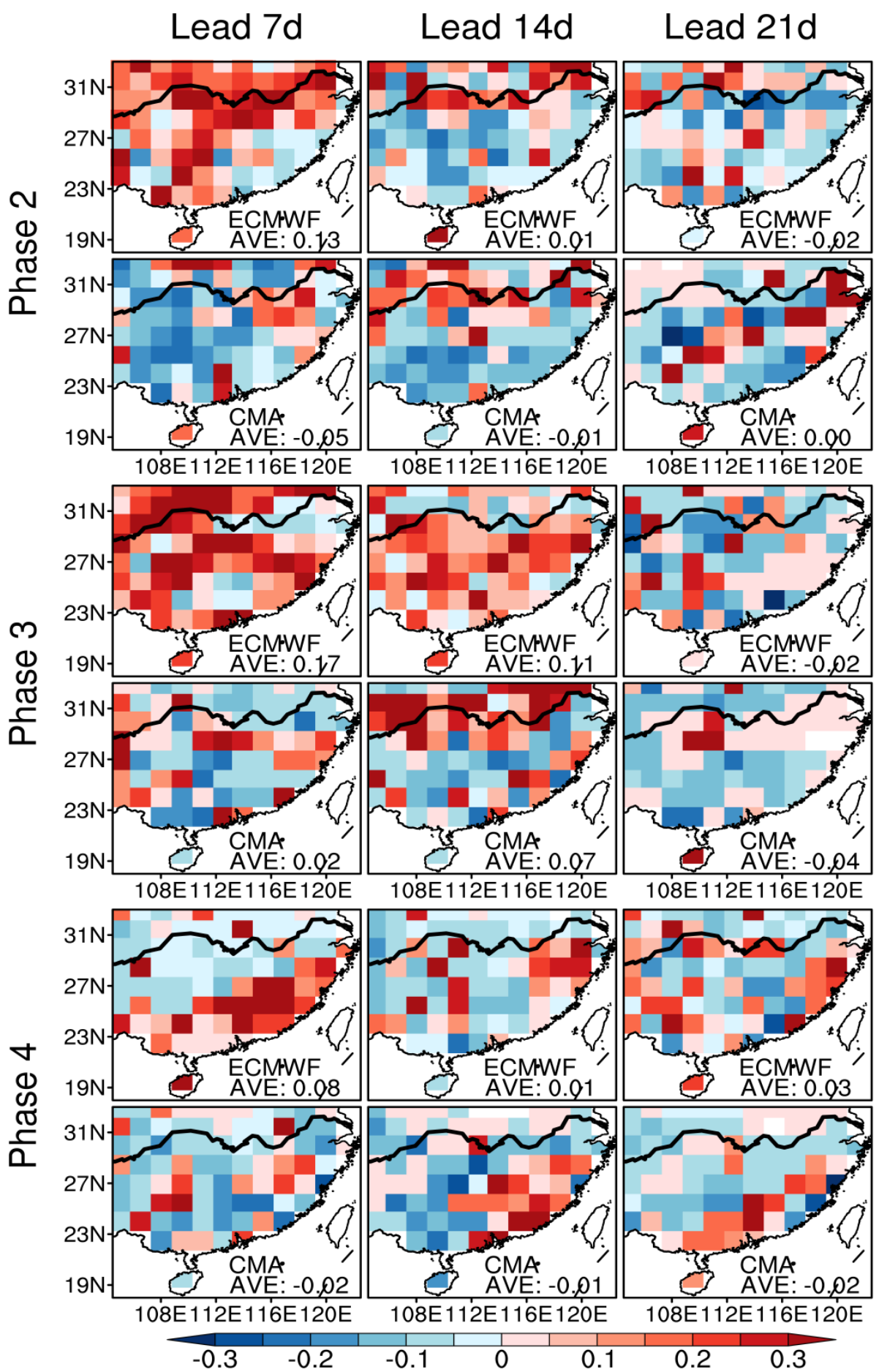

948 Figure 6. Heidke skill score (HSS, shading) of SCER for phase 2 (upper two rows),

949 phase 3 (middle two rows), and phase 4 (bottom two rows) of BSISO1 with respect to

950 the non-BSISO1 period. Panels from left to right are 7-, 14- and 21- lead from

951 ensemble mean predictions, respectively. Areal mean HSS over SC is shown in the

952 bottom of each panel. 
(a) Phase 2

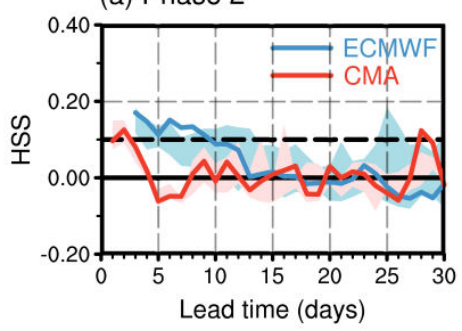

(b) Phase 3

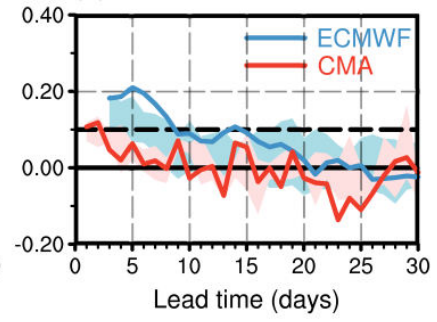

(c) Phase 4

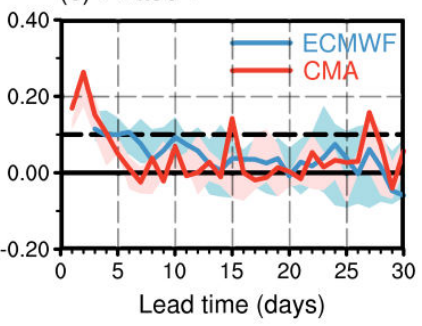

954

956

957

958

959

960

961

962

963

964

965

966

967

968

969

970

971

972

973

974

975

976

Figure 7. As in Fig. 5 but for the areal-mean HSS. 


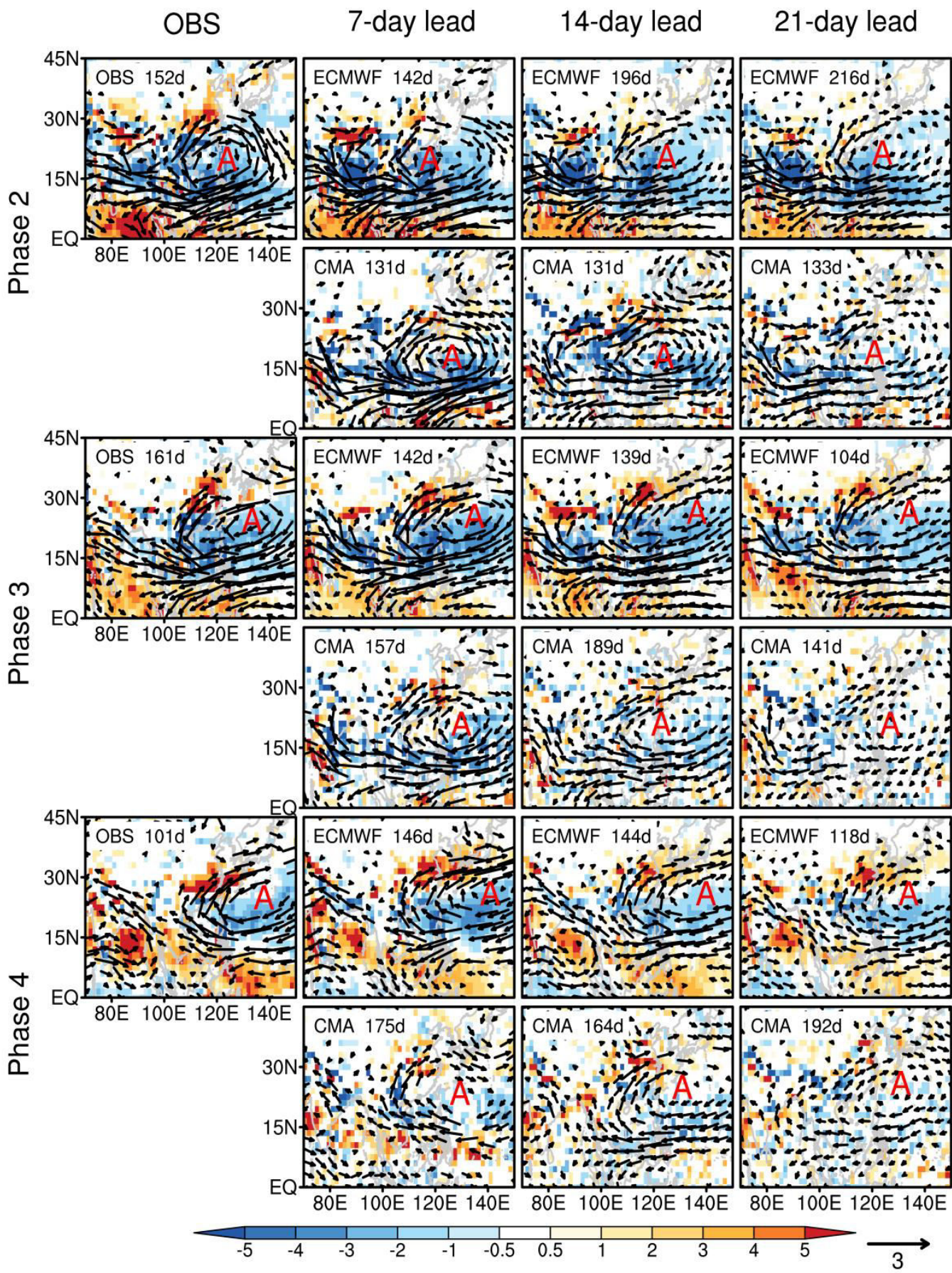

Figure 8. Composites of column-integrated moisture convergence (shading, unit: $10^{-5}$

$979 \mathrm{~m} \mathrm{~s}^{-2}$ ) and 850-hPa wind field (vector, unit: $\mathrm{m} \mathrm{s}^{-1}$ ) anomalies for phases 2 (upper two

980 rows), 3 (middle two rows), and 4 (bottom two rows) of the BSISO1. Panels from left

981 to right are the observation, 7-day, 14-day and 21-day lead of ensemble mean

982 predictions, respectively. Only the fields exceeding the 95\% confidence level are

983 shown. Letter " $A$ " represents the center of the anticyclonic anomaly. The case number

984 for phase composite is shown in the upper-left corner of each panel. 


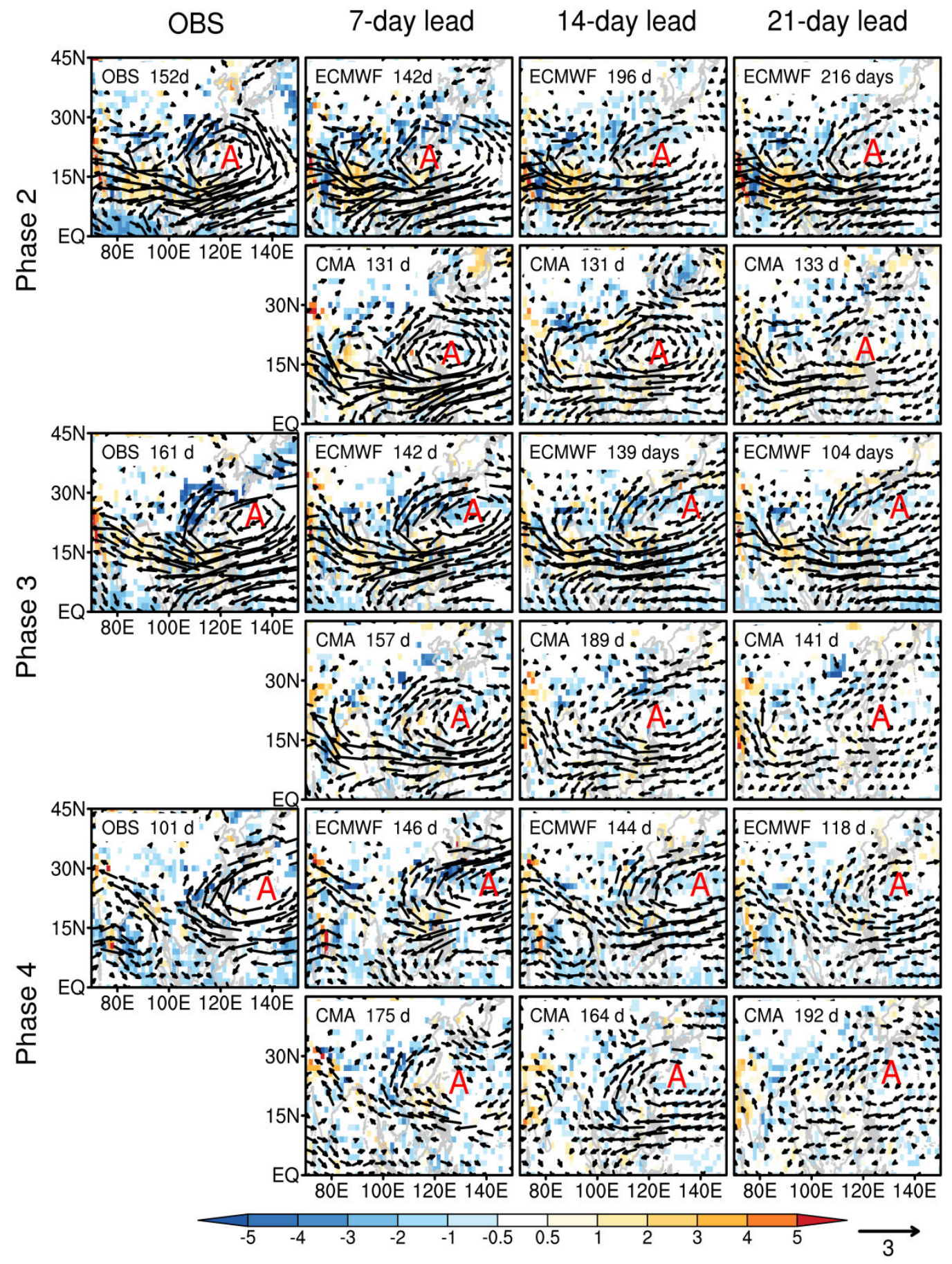

Figure 9. As in Fig. 8, but for the column-integrated moisture advection (shading,

987 unit: $10^{-5} \mathrm{~m} \mathrm{~s}^{-2}$ ) and 850-hPa wind field (vector, unit: $\mathrm{m} \mathrm{s}^{-1}$ ) anomalies. 
(a) Phase 2

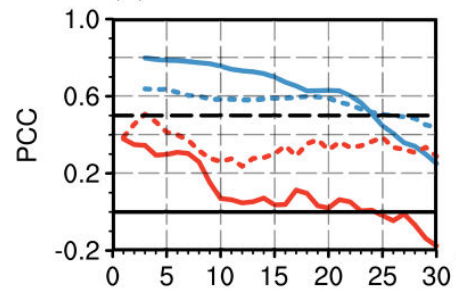

(d) Phase 2

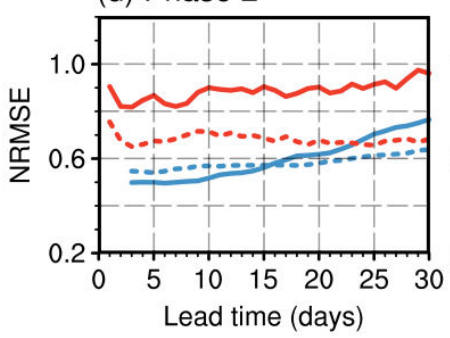

(e) Phase 3

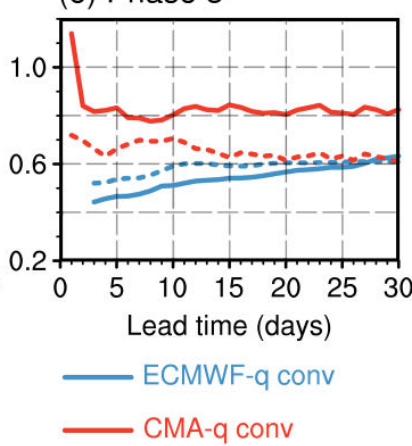

ECMWF-q conv

CMA-q conv

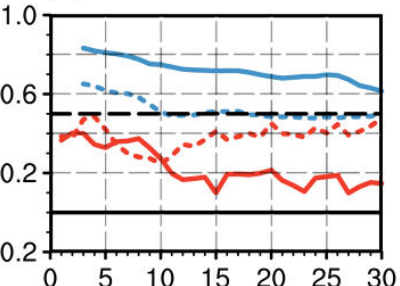

(c) Phase 4

992

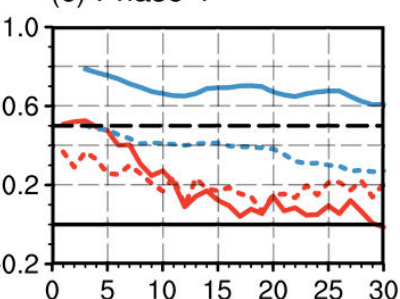

(f) Phase 4

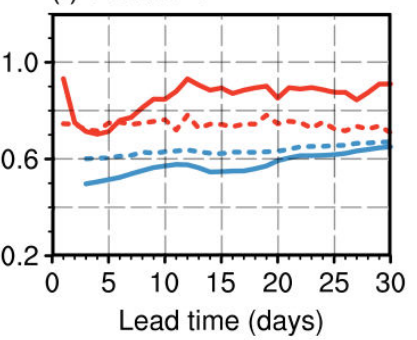

ECMWF-q adv

...... CMA-q adv

993 Figure 10. The PCC skills for the forecasted column-integrated moisture convergence 994 (solid curves) and moisture advection (dashed curves) from ensemble predictions of 995 CMA (red) and ECMWF (blue) in (a) phase 2, (b) phase 3 and (c) phase 4 of BSISO1 as a function of forecast lead time (in day). (d-f) are some as (a-c), but for the NRMSE skills. To quantitatively examine whether the models can correctly predict the moisture field in critical areas, the PCCs and NRMSEs are only calculated over the region with statistically significant signals in observation. 
(a) Phase 2

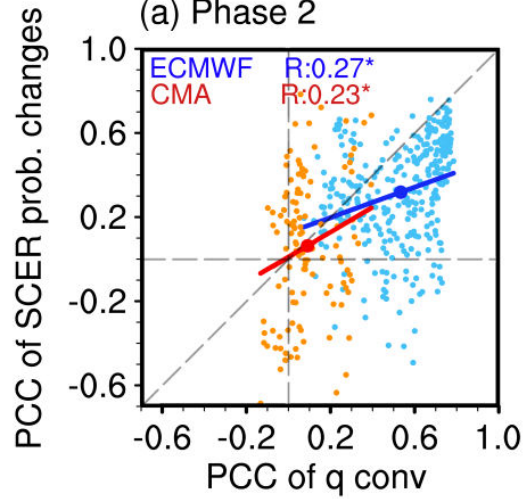

(d) Phase 2

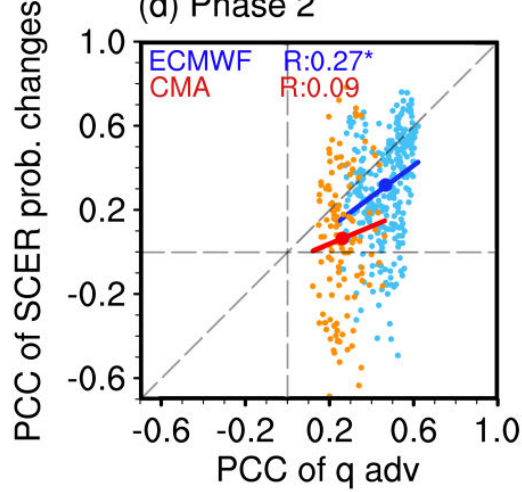

(b) Phase 3

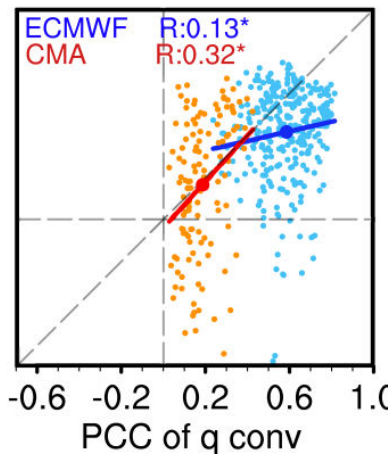

(e) Phase 3

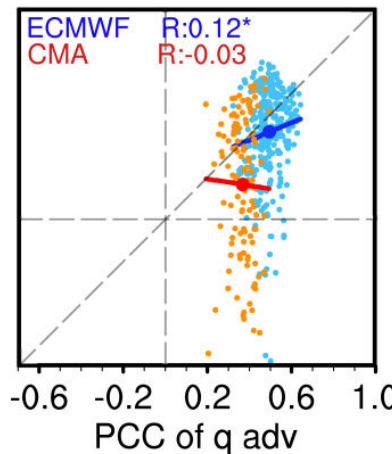

(c) Phase 4

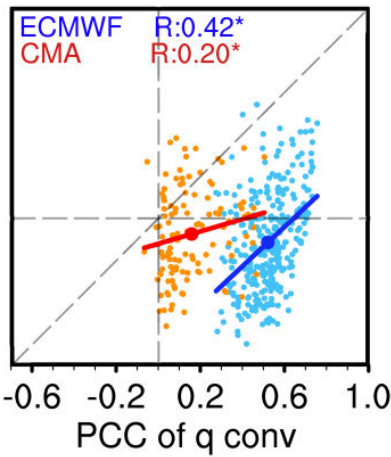

(f) Phase 4

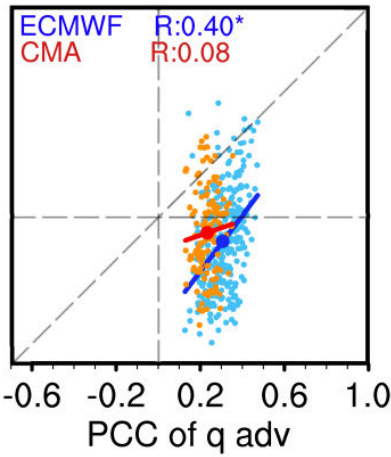

1004

1005

1006

Figure 11. Scatter diagrams for PCC skills of the percentage changes in SCER probability (y-axis) against the column-integrated moisture convergence (x-axis) over the WNP in (a) phase 2, (b) phase 3 and (c) phase 4 of the BSISO1 for all individual members at all forecast lead times from the two models. (d-f) as in (a-c), but $\mathrm{Y}$ axis represents PCC skills of column-integrated moisture advection. The linear fit curves for ECMWF (308 blue dots) and CMA (120 orange dots) are in blue and red, and the large blue and red dots are the averaged PCC for ECMWF and CMA, respectively. The correlation coefficients $(\mathrm{R})$ between PCC skills of percentage changes in SCER probability and those of are column-integrated moisture convergence are given in each panel, and asterisks indicate the $\mathrm{R}$ is significant at the $95 \%$ confidence level.

\section{政}

